To appear in the Journal of Building Performance Simulation

Vol. 00, No. 00, Month 20XX, 1-28

\title{
Multi-Dimensional Simulation of Underground Subway Spaces Coupled with Geoenergy Systems
}

\author{
A. Mortada ${ }^{\mathrm{a}}$, R. Choudhary ${ }^{\mathrm{a}}$ and K. Soga ${ }^{\mathrm{b}}$ \\ ${ }^{a}$ Department of Engineering, University of Cambridge, UK \\ ${ }^{b}$ Civil and Environmental Engineering, UC Berkeley, USA
}

( Third Draft, 17 November 2017)

\begin{abstract}
Old and deep subway lines suffer from overheating problems, particularly during summer, which is detrimental for passenger comfort and health. Geothermal systems could serve as one of the potential energy efficient cooling solutions, compared to energy intensive conventional cooling. The waste heat of the subway tunnel can be harnessed, to provide heating to residential and commercial blocks above the tunnels. This paper presents a multi-scale co-simulation framework for quantifying the amount of useful heat that can be extracted from overheated underground subway tunnels using geothermal heat exchangers. The co-simulation is applied and tested on a representative section of the London Underground's Central Line. The Central Line is modelled using a 1D heat and mass transfer model. The geothermal system, on the other hand, is represented using a 3D finite element model. The 1-D and 3-D models are cosimulated, using the subway tunnel's outer wall temperatures as boundary conditions. The model is run parametrically to identify the best arrangement and depth of geothermal heat exchangers for extracting excess heat from subway tunnels. Results show that the depth of $15 \mathrm{~m}$. below the tunnel is sufficient for vertical closed loop heat exchangers to yield temperature drop of $4{ }^{\circ} \mathrm{C}$ in the subway tunnel and platforms. Partially insulated boreholes, alternating between extracting and injecting heat into the soil, are also assessed for their potential to provide heating and cooling demand simultaneously and improve the overall geothermal system efficiency. The heat extracted along a representative section of the tunnels is compared to the heating demand of the buildings above ground.
\end{abstract}

Keywords: Subway Environment; Multi-dimensional Simulation; Geothermal Systems

\section{Introduction}

Underground subway systems provide an efficient high capacity public transportation method for commuters within dense urban areas. This form of public transportation plays a significant role in reducing road congestion as well as filling the gaps in insufficient over ground public transport and road capacity. Passengers using underground subway systems are subjected to enclosed and crowded environments that must be controlled to maintain tolerable temperatures and ventilation.

Modern subway stations and trains are cooled using conventional air conditioning, providing acceptable levels of passenger comfort. However, deep and old subway systems suffer from overheating problems because they were built before the invention of modern mechanical ventilation and air conditioning, resulting in passenger discomfort and health issues during summer conditions (Gilbey, Duffy, and Thompson 2011). These systems were not designed to handle the high numbers of passengers and train traffic in current congested cities such as London or New York. The oldest deep subway lines such as the London Underground (1863), Paris (1900), New York (1902), Berlin (1902), and Moscow Metro (1935), commonly experience overheating problems (Griffiths 2006). When high ambient temperatures are combined with heat rejected from train braking and passenger traffic, the temperatures of the tunnels and platforms rise substantially above tolerable levels. The London Underground, particularly the deep sections have become uncomfortable during 
summer due to congestion and poorly ventilated tunnels, where during the 2006 European heat wave, temperatures as high as $47^{\circ} \mathrm{C}$ were recorded (Griffiths 2006). Retrofitting old deep subway systems with air conditioning is often infeasible because the tunnels only allow enough room for trains. Furthermore, heat rejected from air-conditioning in these narrow tunnel spaces could in fact further exacerbate the overheating problems.

As a result, temperatures in old subway tunnels (and surrounding ground) have increased over long term (Botelle, Payne, and Redhead 2010). The shallow ground surrounding an old overheated subway system thus has a large potential of low enthalpy energy that can be used for low-grade heating and cooling purposes. Advances in ground source heat pump configurations makes it possible to consider extracting this geothermal energy in an efficient manner (Nicholson et al. 2014). Recent applications have shown successful integration of geothermal systems with underground tunnels using heat exchanger pipes in tunnel lining, such as in the Channel tunnel, Lainzer tunnels (Franzius and Pralle 2011), and Stuttgart Metro U6 (Schneider and Moormann 2010). Other configurations of geothermal systems integrated with city's underground infrastructure include foundation piles, diaphragm walls, and base slabs as ground heat exchangers (Adam and Markiewicz 2009), (Brandl 2006), and (Fry 2009).

In all of the aforementioned cases, geothermal systems are best integrated into modern subway systems during construction phases, as they are embedded within the structural form. Introducing them as a retrofit strategy in existing subway structures is not only uneconomical but often infeasible. In this paper, we investigate instead the use of stand-alone standard closed loop vertical Ground Source Heat Exchangers (GHE) to extract excess heat from an old and deep subway tunnel. Because vertical GHEs are physically and structurally independent of the underground subway structure, they can be positioned flexibly around the tunnels. Furthermore, vertical closed loop GSHP systems are standard in urban areas because they can be easily installed, do not require large spaces, and yield good system efficiency (Kavanaugh and Rafferty 1997). In the UK, they also qualify for subsidies under the UK Government's Renewable Heat Incentive Scheme (EST 2014). To evaluate the potential of vertical GHEs for usefully extracting excess heat from the subway tunnels, one must be able to quantify the net gains: How much useful heat can be feasibly extracted from underground tunnels over a time period? What is the optimal GHE set-up that could maximize heat extraction? and What are the resulting temperature drops in the underground tunnels and platforms? This paper demonstrates a framework designed to answer these questions through simulation modelling.

Environmental simulation of underground transit systems is typically 1-D (Brinckerhoff 2001) \& (EQUA 2006). On the other hand, the behaviour of underground heat exchangers (GHEs) is better quantified via 3D finite element models (FEMs). This paper couples a 1D model of a subway line with a 3D FEM model of vertical ground heat exchangers. The 1D subway model represents spatially averaged transient heat and air flows in the underground, while the FEM model simulates vertical close-loop GHEs next to the subway tunnels. The two models are co-simulated such that information is passed back and forth through a common temperature boundary layer at the outer tunnel walls until both models converge. As a result, the cooling effect of vertical GHEs on the underground climate is examined. In addition, the heat extraction rates of the GHEs placed next to the subway tunnels are compared with standard GHEs. Different arrangements and distances of the GHEs with respect to the tunnels are also examined to achieve the best heat extraction and cooling in the tunnels and stations simultaneously. Finally, partially insulated GHEs are investigated to provide for both heating and cooling demand because the need to extract heat from the subway is most during the summer months, when demand from building is also for cooling.

As illustrative study, the London Underground's Central line is selected as representative of an old subway system that suffers from overheating and ventilation problems. The Central Line is one of the busiest line of the London Underground, and suffers from over heating problems 
particularly during summer conditions, where temperatures above $35{ }^{\circ} \mathrm{C}$ have been recorded in some areas (Gilbey et al. 2011). Figure 1 illustrates the hottest spots on London's underground system during the month of August 2013, as revealed to commuters by Transport for London (TfL). In 2015, TfL started distributing bottles of water to manage passenger discomfort and dehydration during summer as part of "Beat the Heat and Travel Better" campaign (TfL 2014). Technical efforts to alleviate the overheating problems in the London Underground have been so far limited to expanding the ventilation shafts and installing fans with higher air exchange rates. These strategies - though helpful - have been insufficient. Installing air-conditioning in the trains of the deep and old lines is particularly challenging because current sizes of air-conditioning units are difficult to fit, and the exhausted heat from these units would exacerbate the overheating problems in the tunnels and platforms. Given these challenges as well as the potentially favourable context for geothermal systems, the Central Line of the London Underground is a good candidate to investigate if waste heat from the underground metro systems can be usefully extracted through ground source heat pumps.

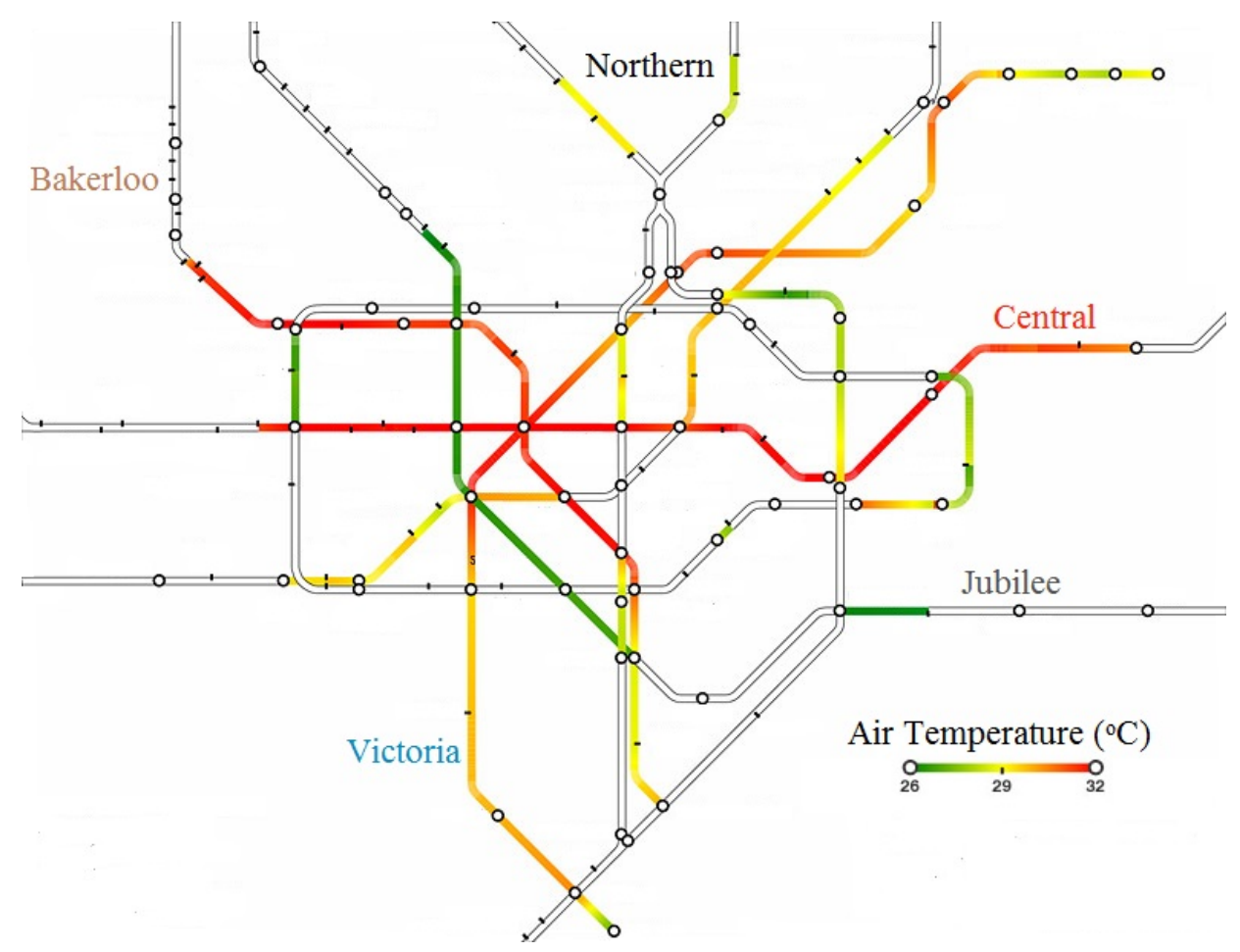

Figure 1. Average Air Temperatures in London Underground for August 2013 at peak time 16:00 - 19:00 pm [CITE SOURCE]

\section{Modelling Methodology}

\subsection{The Subway 1D Model}

The underground subway environment experiences complex thermal and fluid interactions that are transient in nature. 1D models are suitable for simulating the underground's environment on a large scale of kilometres, since they use a simplified representation of the tunnels, ventilation ducts, and the surrounding soil. Consequently, 1D models cannot provide accurate analysis of more localized optimization problems, such as redesigning ventilation shafts, or particular tunnel sections (Kim and Kim 2009). Currently, the Subway Environment Simulation Program (SES) 1D software enables underground tunnel designers to estimate the temperatures, airflows, humidity, as well as air conditioning requirements for subway systems (Brinckerhoff 2001). The SES was developed 
by Parsons Brinkerhoff under the supervision of the United States Department of Transportation in 1976 (Brinckerhoff 2001). IDA Tunnel (EQUA 2006) is the most recent 1D subway simulation software, with fundamental equations and concepts based on the SES. IDA tunnel resolves many of the SES's drawbacks and has post-processing capabilities, better visualization of the subway system, and additional features such as pollutant dispersal simulations (EQUA 2006). IDA Tunnel is employed in this paper to model the Central Line.

\subsubsection{Representation of the Subway Line}

Even with a 1-D model, simulating an entire subway line would be cumbersome and computationally penalizing. The Central Line consists of 16 stations underground, and simulating the environment of each tunnel and station would take hours of simulation for a single day. Therefore, a representative section of the Central Line is modelled to emulate the characteristics of this subway line as a whole. The representative model, shown in Figure 2, constitutes of $4015 \mathrm{~m}$ of bi-directional tunnels (westbound and eastbound) and 3 platforms of $140 \mathrm{~m}$ in length each. In this model, tunnel sections A \& D (which are open to ambient) and platforms $2 \& 3$ are close to the final exits of the tunnel, and their purpose in the model is to homogenize the underground climate conditions and therefore provide feasible boundary conditions for tunnel sections B \& C and platform 1 . The tunnel lengths between platforms 1, $2 \& 3$ are typical of the Central Line stations within London. The middle station box at platform 1 is modelled in detail based on the old Tottenham Court Road station schematics. The rest of the Central Line stations follow similar design patterns in terms of passenger entrance, ticketing hall, escalators and passages.

The tunnel walls of the Central Line are made primarily of $2 \mathrm{~cm}$ thick cast iron rings followed by a grout layer, and the tunnel inner diameter is $3.57 \mathrm{~m}$. The upper first floor of the station is made of a composition of brick walls and glazing. The ventilation in the Central Line is composed of high capacity ventilation fans and shafts (marked on Figure 2) which are operated at full capacity 24 hours a day in exhaust mode at approximately $30 \mathrm{~m}^{3} / \mathrm{s}$ all around the year (Gilbey et al. 2011). The soil properties are taken to be that of London clay having thermal conductivity $=1.6 \mathrm{~W} / \mathrm{m} . \mathrm{K}$, density $=1800 \mathrm{Kg} / \mathrm{m}^{3}$, and thermal capacity $=1200 \mathrm{~J} / \mathrm{Kg} . \mathrm{K}$ (Webb et al. 2009).

The various heat sources in in every section of the subway line are specified in the model as inputs. The 1992 train stock's specifications and dimensions were obtained from reports provided by TfL (TfL 2010). The Central Line train schedules were also obtained from TfL; There are 462 trains/day and 30 trains/hour operating on the two routes at peak times (8-9 am \& 5-6 pm): eastbound and westbound. The passenger numbers in the station are modelled based on London Underground's reports that provide the numbers of passengers entering/exiting the station throughout a typical day (TfL 2011). The passengers are assumed to be walking on their way from the station entrance to the platform and standing on the platform whilst waiting for the train. Their metabolic rate is accordingly specified to be $207 \mathrm{~W}$ and $126 \mathrm{~W}$ respectively (ASHRAE 2001). The passengers are assumed to be distributed equally across the station sections: $1 / 3$ are in the upper ticket hall, $1 / 3$ in the escalators and passages, and $1 / 3$ in the platforms. Other heat sources in the station include lights, signs, advertisements, lifts, escalators and ticketing machines, while the tunnels contain ambient lights and stop signs. The model shows that the largest cumulative portion of heat source in the Central Line is due to train braking and the passengers. At peak times, braking contributes towards approximately $61 \%$ of heat dissipation in the subway system, as the currently used train stock has no brake regeneration. Passenger traffic contributes approximately $34 \%$ to heat gains inside the station and platforms (Mortada, Choudhary, and Soga 2015).

\subsubsection{Boundary Conditions, Simulation Setup, and Model Verification}

The model's boundary conditions consist of the outside ambient climate conditions and the surrounding soil. The weather profiles used are statistical averages (TMY files), based on recorded 


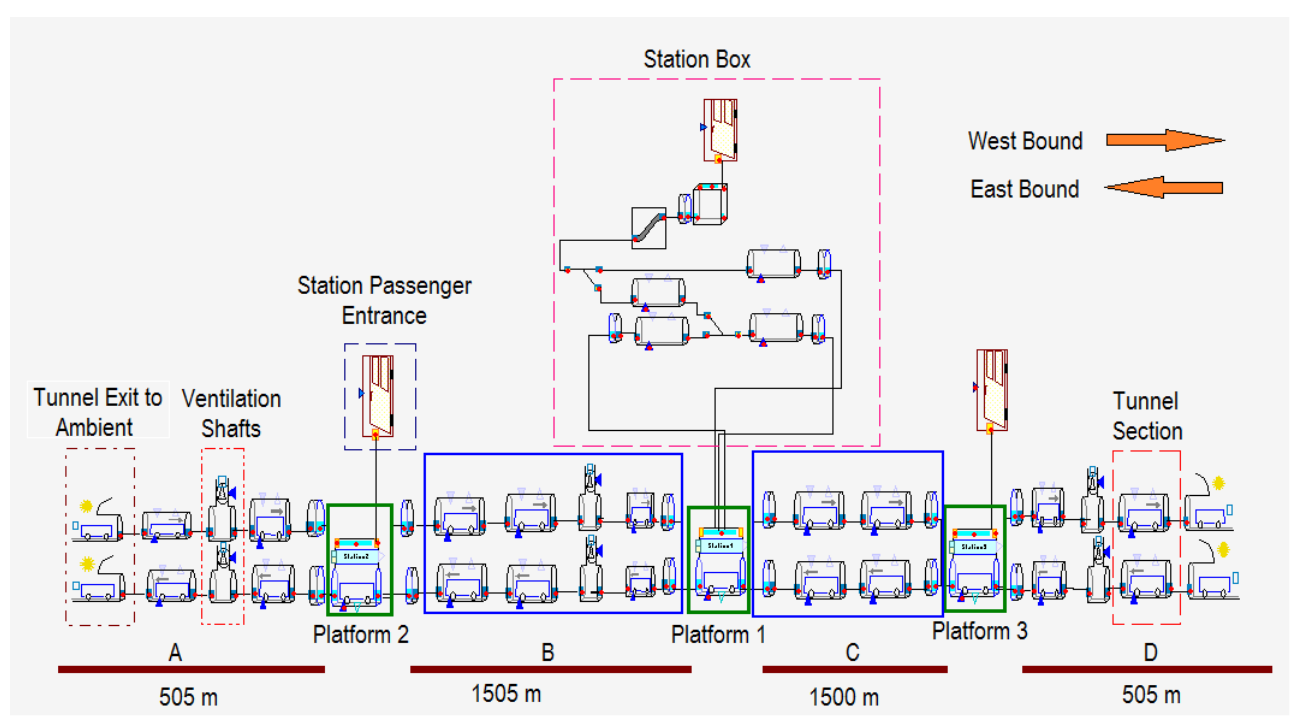

Figure 2. Schematic of the Central Line for 1D Simulation

climate conditions between 1996-2010. The weather data input into the model includes: air temperature, relative humidity, wind speed, and wind direction. The outer ambient conditions act on the tunnel's entry/exit points, the entrances of station boxes, and the ventilation shafts. The background soil temperature is set to $14{ }^{\circ} \mathrm{C}$, based on recorded temperature measurements. The soil is assumed to be infinitely thick because the Central Line stations are typically at a depth of 30 $\mathrm{m}$, where the background soil temperatures are fairly stable. The model assumes no interference from other lines in the station. Also, the cross service tunnels between the eastward and westward bound tunnels are neglected, since their effect is localized.

Since the central line has been running for over 114 years, the initial ground temperature profile upto the year of 2012 needs to be established. To accomplish this, the simulation is run in so-called 'long-term mode' to estimate the ground temperatures. This type of simulation simplifies the model so that computations can run at an acceptable time. During the 'long-term mode' the time scale for the heat transport in the surrounding bedrock is rescaled to yield a faster transport, and therefore, temperature developments which in reality cover years, will in simulations be shortened to hours or days. A way of thinking about this is that the material properties of the ground are adjusted, so that a long term temperature field is established with only a small fraction of the amount of energy that normally would be required. The model is run in long-term mode for 114 years and then simulated in detail, at a time scale of minutes, for the year of 2013. To verify the model, the resulting simulated tunnel and platform temperatures have been compared with actual temperatures in the Central Line for the same year (obtained from TfL) and presented in (Mortada, Choudhary, and Soga 2015). The simulated temperatures in both the tunnels and platform are very close to the measured data, when fitted linearly (Mortada, Choudhary, and Soga 2015). The model predicts a slightly cooler platform temperature at low ambient temperatures by $0.75{ }^{\circ} \mathrm{C}$ when the outer ambient temperature is $0^{\circ} \mathrm{C}$. This difference can be attributed to air-heated train cabins during winter which were not included in the model, and nor were additional sources of spot/localised heating in areas of the subway stations (eg. information and ticketing offices). The simulated tunnel temperatures matched the measured data, except for a slight $0.5^{\circ} \mathrm{C}$ higher temperature prediction at $30{ }^{\circ} \mathrm{C}$ ambient temperatures. This slight difference is attributed to the simplification of the tunnel system in the model. Indeed, cross tunnels between eastbound and westbound tunnels were neglected in the 1D model. Thus, the model has slightly less tunnel volume than the actual tunnel, but similar amount of heat dissipation. 


\subsection{D Finite Element Model of Ground Heat Exchangers}

Several 1D, 2D and 3D simulation models, both numeric and analytic, have been developed to model a single or an array of underground geothermal systems, in both transient and steady state conditions (Connolly et al. 2010). Widely used classical 1D heat transfer models are the Kelvins line source model, and the cylindrical heat source model, which use the Fourier law of heat conduction. The line source theory assumes the vertical geothermal borehole as an infinite line source of heat in the ground, and the ground is assumed to be an infinite medium with an initial uniform temperature. The cylindrical heat model assumes a cylindrical borehole with infinite length buried in the ground, where the model's governing equation can be analytically solved through either a constant heat transfer rate across the borehole surface or a constant borehole surface temperature (Carslaw and Jeager 1959) \& (Ingresoll and Plass 1948). (Hellstrom 1991), (Kavanaugh 1995),(Bernier et al. 2004), and (Hikari, Ryuichi, and Takashi 2004) have focused on making the 1D analytic borehole models more accurate and comparable to numerical ones (Fayegh and Rosen 2012). A 2D finite line source model was established by (Zeng, Diao, and Fang 2002), while (Cui, Yang, and Fang 2006) and (Yi et al. 2010) developed finite 3D vertical borehole analytic models (Yi, Ping, and Zhaohong 2012).

The long-time step g-function model was developed by (Eskilson 1987) to model boreholes for thermal storage applications. The $\mathrm{g}$-function is essentially a normalised step-response function that describes the relationship between the average borehole temperature and a step in the extractionrejection for a defined configuration of boreholes. In this approach, the complex geometry of a borehole is simplified as a cylinder with a finite length and diameter. A single temperature is used to represent the borehole wall temperature. The thermal conductivities and capacities of all the different materials inside a borehole, including fluid, pipes and grout, are neglected. The longtime step g-function models provide an efficient solution to simulate borehole fields with defined configurations over long timescales, ranging from one month to several years. In order to expand the application of the long-time step g-function model, (Yavuzturk 1999) developed a two-dimensional numerical model on a polar grid to compute the so-called short time step g-function. The model that combines the short time step g-function and the long-time step g-function was implemented in GLHEPro (Spitler 2000), a design software for vertical borehole ground loop heat exchangers. However the borehole geometries modelled by G-functions remained simple, were (Eskilson 1987) calculated over 200 g-functions for multiple Boreholes arranged in different shapes, such as in a line, in a rectangle, and in a square, with different distance between two boreholes.

Significant simplifications in the analytical borehole models render them unsuitable for complex geometries and short-time step transient simulations of boreholes (Yi, Ping, and Zhaohong 2012). Numerical borehole models are attractive when the aim is to obtain high-resolution solutions or conduct parametric analysis at small time-steps. However, numerical models need to be setup efficiently in terms of symmetry, boundary conditions and mesh distribution, since they can be computationally time penalizing. For example, (Nora, Shemin, and McCartney 2016) used symmetry to model arrays of boreholes to asses their thermal energy storage in the soil in combination with solar thermal energy harvesting using finite element methods. Therefore, to model the transient thermal interactions between multiple vertical boreholes and subway tunnels, a 3D finite element model is developed using 'Comsol', which is a general purpose multi-physics simulation software.

\subsubsection{D Model Geometry, Setup and Boundary Conditions}

A typical vertical close-loop borehole (heat exchanger) design that adheres to DECC's Microgeneration Certification Scheme standards is used (DECC 2011). As seen in Figure 3 and Figure 4, the model consists of two tunnels, $10 \mathrm{~m}$ apart, representing the eastbound and westbound tunnels of the London Central Line. The boreholes are $13 \mathrm{~cm}$ in diameter, and $100 \mathrm{~m}$ deep. They are located $20 \mathrm{~cm}$ from the tunnel outer walls: the primary aim of the boreholes is to cool the tunnels, and the 
optimum way to achieve this is by placing them as close as possible to the tunnel walls. Boreholes are placed on both sides of the two tunnels, such that they are $6 \mathrm{~m}$ apart in the direction of the tunnel and $4.16 \mathrm{~m}$ apart across a tunnel (Figure 3). For this particular analysis, the boreholes are exclusively placed on the sides of the entire tunnel sections $\mathrm{B} \& \mathrm{C}$ and not the station platforms. The soil properties are taken to be that of London clay and are assumed uniform (variation of the soil thermal properties due to local moisture content are neglected). The background soil temperature is $14^{\circ} \mathrm{C}$ (Webb et al. 2009) at $50 \mathrm{~m}$ distance from the tunnel centres in all directions, except for the upper ground surface temperature which is assumed to follow the London ambient air temperatures. The initial temperature of the borehole surfaces is assumed to be constant at 0 ${ }^{\circ} \mathrm{C}$. This assumption is commonly used in modelling soil temperatures surrounding the boreholes (Fayegh and Rosen 2012), where $0{ }^{\circ} \mathrm{C}$ temperature is a typical average borehole refrigerant fluid temperature (DECC 2011). For this initial proof-of-concept model, the geothermal system (boreholes) are assumed to be always operating, though this is unrealistic since geothermal systems usually operate based on heating/cooling demand.

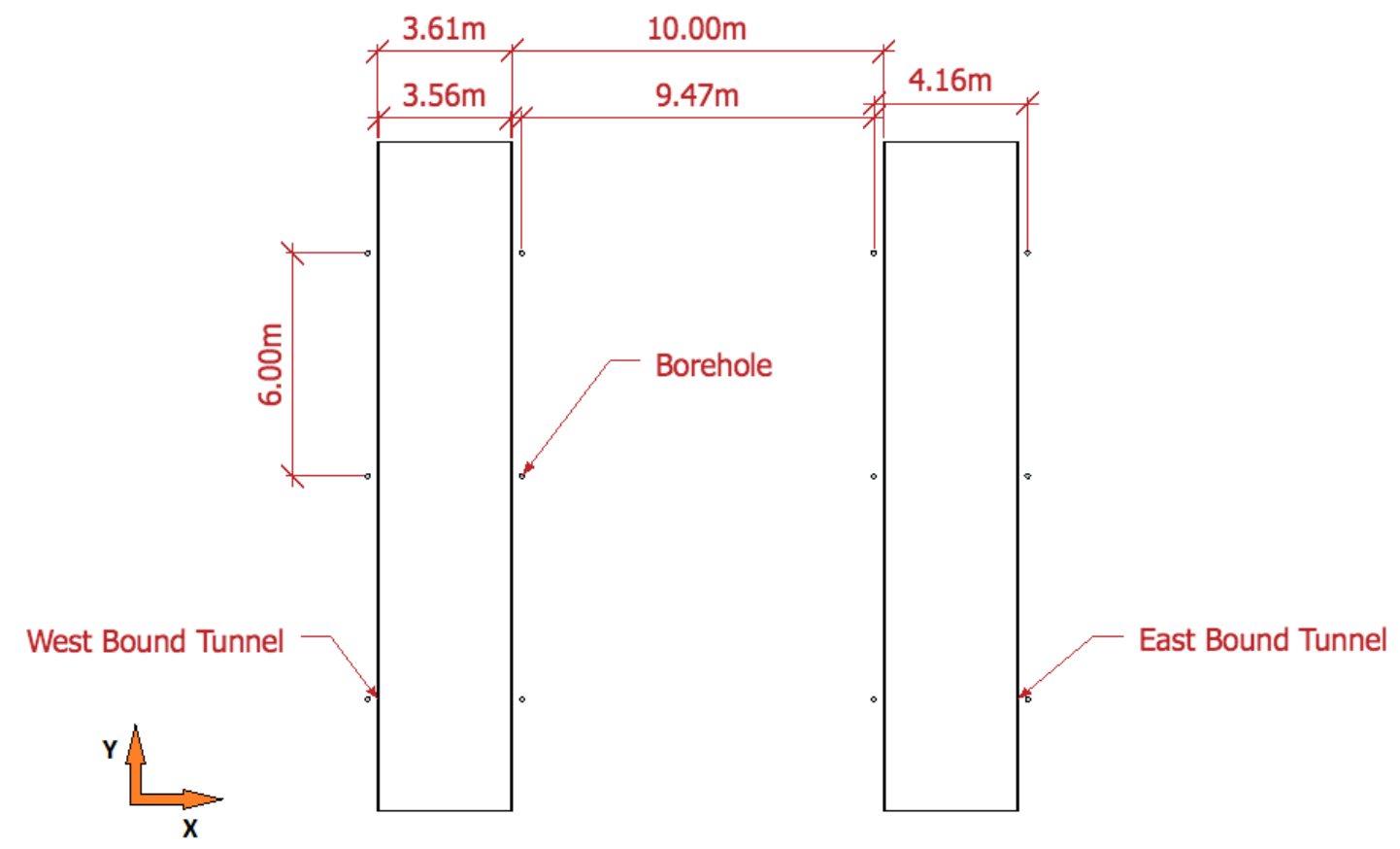

Figure 3. Schematic of the vertical borehole around the Central Line tunnels.

Figure 4 shows the cross section view of the model, where the two tunnels are in the centre, and each tunnel has a set of vertical $100 \mathrm{~m}$ deep boreholes $20 \mathrm{~cm}$ from the tunnel outer wall. The circular sections that surround the tunnels in Figure 4 are for specifying initial soil temperatures at specific distances. These are obtained from the 'long term simulation' (the soil temperatures for the Central Line after 114 years of operation, as explained in section 2.1.2). The meshing of the 3D ground model is tetrahedral and is set to 'very fine' between the tunnel walls up to a radius of $19 \mathrm{~m}$ from the tunnel center, which has a minimum element size of $0.02 \mathrm{~m}$ and a maximum element size of $2 \mathrm{~m}$. Beyond the radius of $19 \mathrm{~m}$, the mesh is set to be 'fine', which is coarser having a minimum element size of $0.15 \mathrm{~m}$ and a maximum element size of $3.5 \mathrm{~m}$. Also, symmetry is applied along the z-y planes in both the positive and negative direction in order to model a continuous array of boreholes on the sides of the two tunnels. Hence, the 3D model contains 4 boreholes in total, and the remaining borehole array across the tunnel is modelled using symmetry (Figure 4). Simulation for 1 year iteration on a $2.7 \mathrm{GHz}$ quad core computer takes 31 hours. 


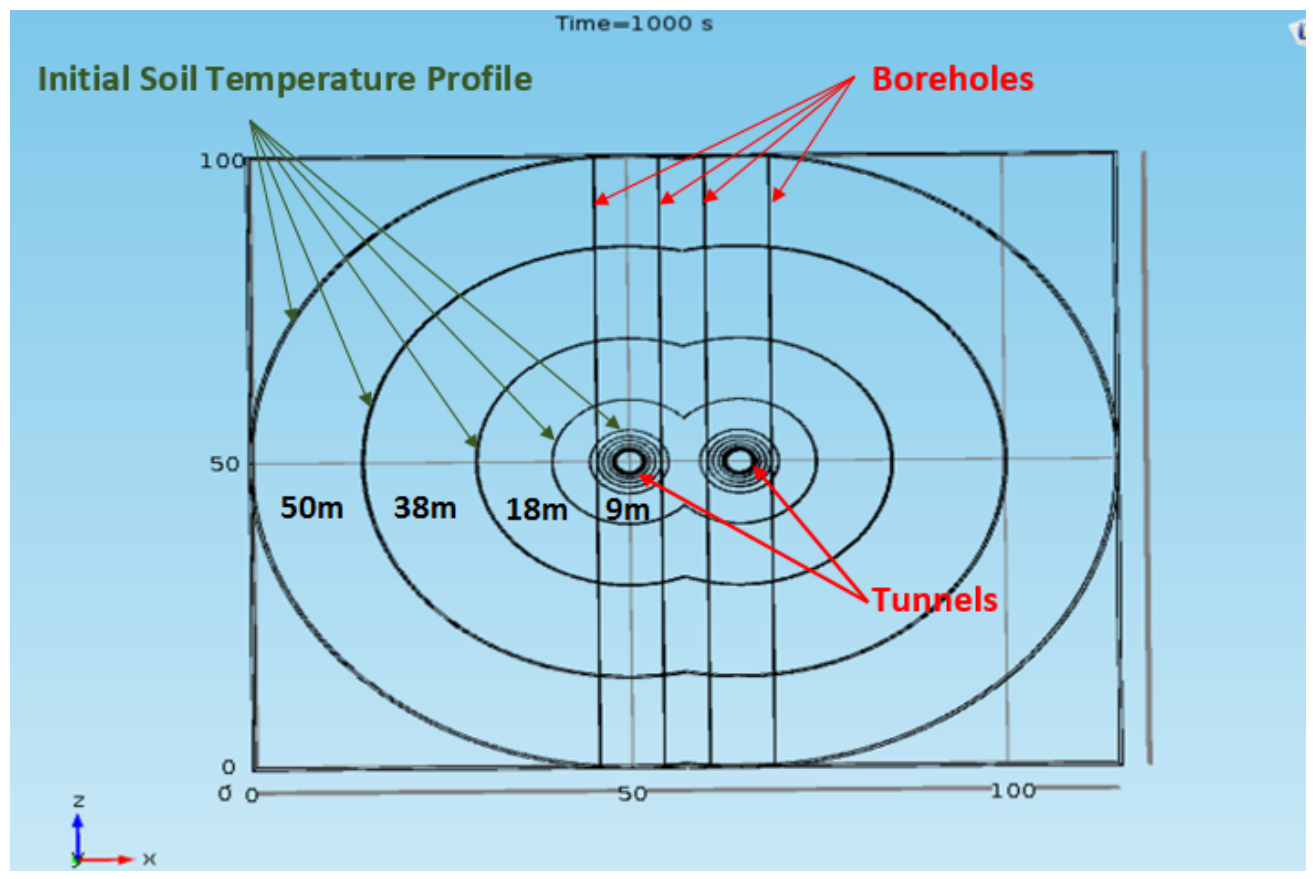

Figure 4. Cross section of the vertical boreholes as modelled.

\subsection{D Subway and 3D Borehole Model Co-simulation}

After the 1D subway model is simulated for 114 years on the so-called 'long-term mode', the radial soil temperature profile thus obtained is used as initial soil temperatures in the 3D FEM model of the boreholes. The outer tunnel wall temperatures of sections B \& C output by the 1D one year simulations of the subway line are used as boundary temperatures in the 3D FEM model. The $3 \mathrm{D}$ FEM model of the boreholes is simulated over the same time period (1 year) and time-steps (1 min) as that of the 1D subway line model. The average radial soil temperature output by the 3D FEM model at $20 \mathrm{~cm}$ from the outer tunnel walls are then used as boundary temperatures in the $1 \mathrm{D}$ subway model sections B \& C. The 1D subway model is re-simulated with the same time interval, but with the updated radial soil temperature boundary from the 3D FEM model of the boreholes. The newly obtained outer wall temperature is re-input in the 3D FEM model of the boreholes. This process is repeated until the change in the outer tunnel wall temperature in the 1D model of the subway line becomes negligible after a number of iterations, indicating that both the 1D and 3D models have converged. This co-simulation process is illustrated in (Figure 5).

Figure 6 shows the outer tunnel wall temperatures for the month of January as a result of consecutive iterations using the coupled co-simulation. In the first iteration (IT1) the outer tunnel wall temperatures drops significantly. Over subsequent iterations, the temperature decrease is less, until it is negligible (IT11), indicating that the transient co-simulations have converged. Since the 3D FEM model of the boreholes is setup such that that the vertical boreholes start operation at the beginning of January, the outer wall temperatures are identical at the beginning of January. The difference, at subsequent time-steps, between the outer wall temperatures of the original model (without boreholes) and the converged co-simulation (shown as IT11 in Figure 6) is indicative of the cooling effect (or heat extraction) due to the boreholes. Indeed, Figure 6 shows, by mid-January, a $2{ }^{\circ} \mathrm{C}$ difference in the outer wall temperatures due to the vertical boreholes. This cooling effect is more significant during summer months.

The temperatures shown in Figure 6 are obtained by co-simulating the 1D subway line model and the 3D FEM model of the boreholes over a time period of a month, starting January. As the two models converge, the co-simulation is moved to the following months, until the entire year is 


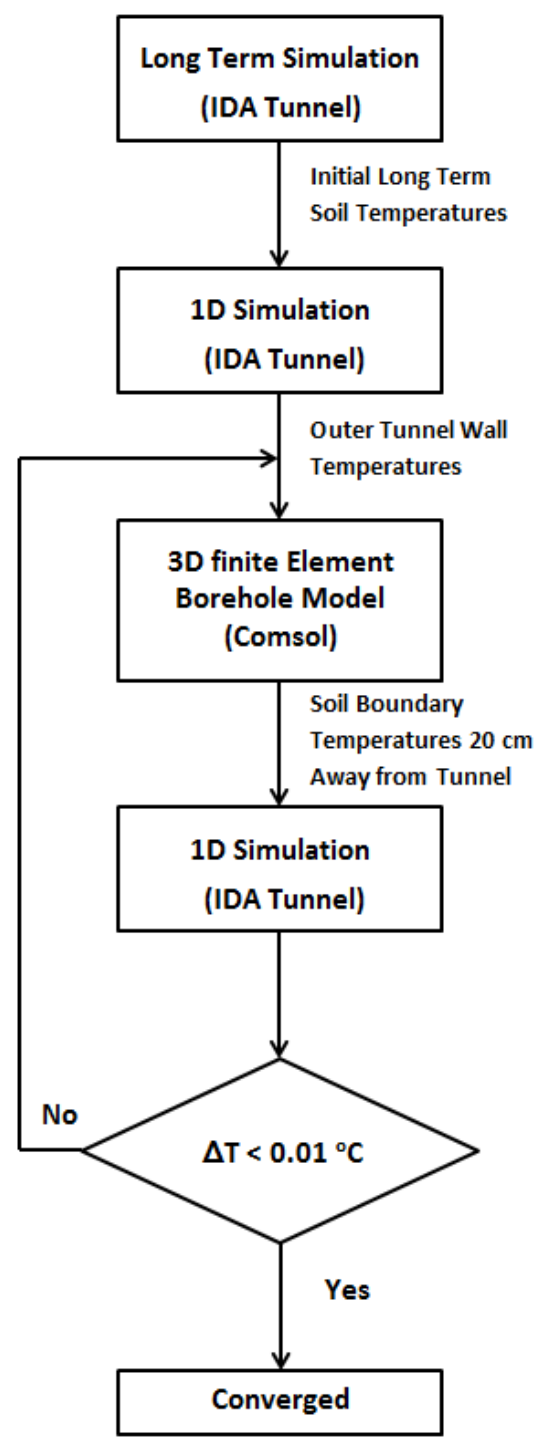

Figure 5. Co-simulation Process of the 1D Subway and 3D Borehole Models.

covered. However, simulating an entire year using monthly time periods is time-consuming, and it would be more efficient to simulate them over longer time periods. Consequently, the two models are also co-simulated with time periods of 3 months for an entire year, and the results are compared to the single month simulations. The converged outer tunnel wall temperatures for 1 month and 3 month time period iterations are compared in Figure 7 . The outer tunnel temperatures were almost identical for both iteration intervals over the periods of January, February, and March. Thus, the two models can be co-simulated over longer time period without affecting the accuracy of the solution. A 4 month time period was used to co-simulate the results shown in the following section. Consequently, the total number of co-simulations for the entire year was 33 iterations, since every four month required 11 iterations to converge. 


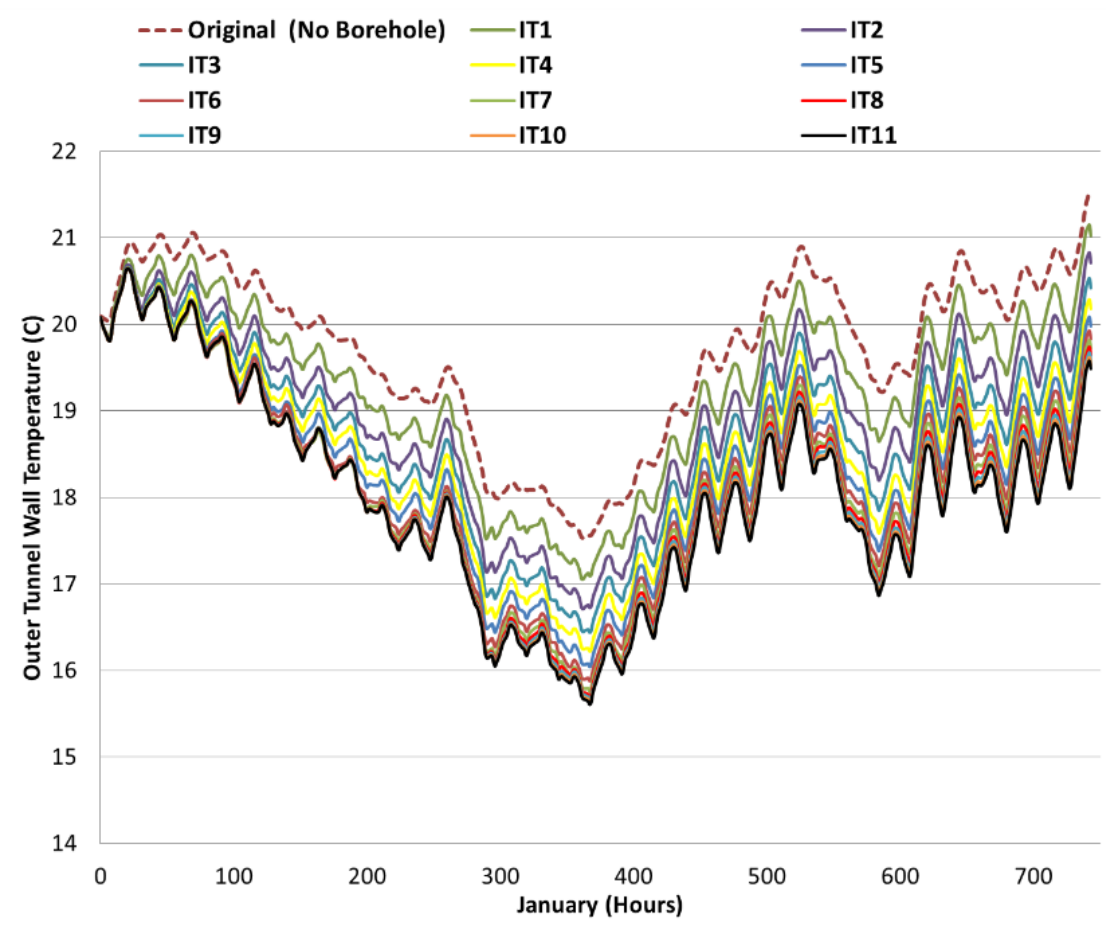

Figure 6. Variation of the outer tunnel wall temperature for the month of January with every co-simulation iteration (IT).

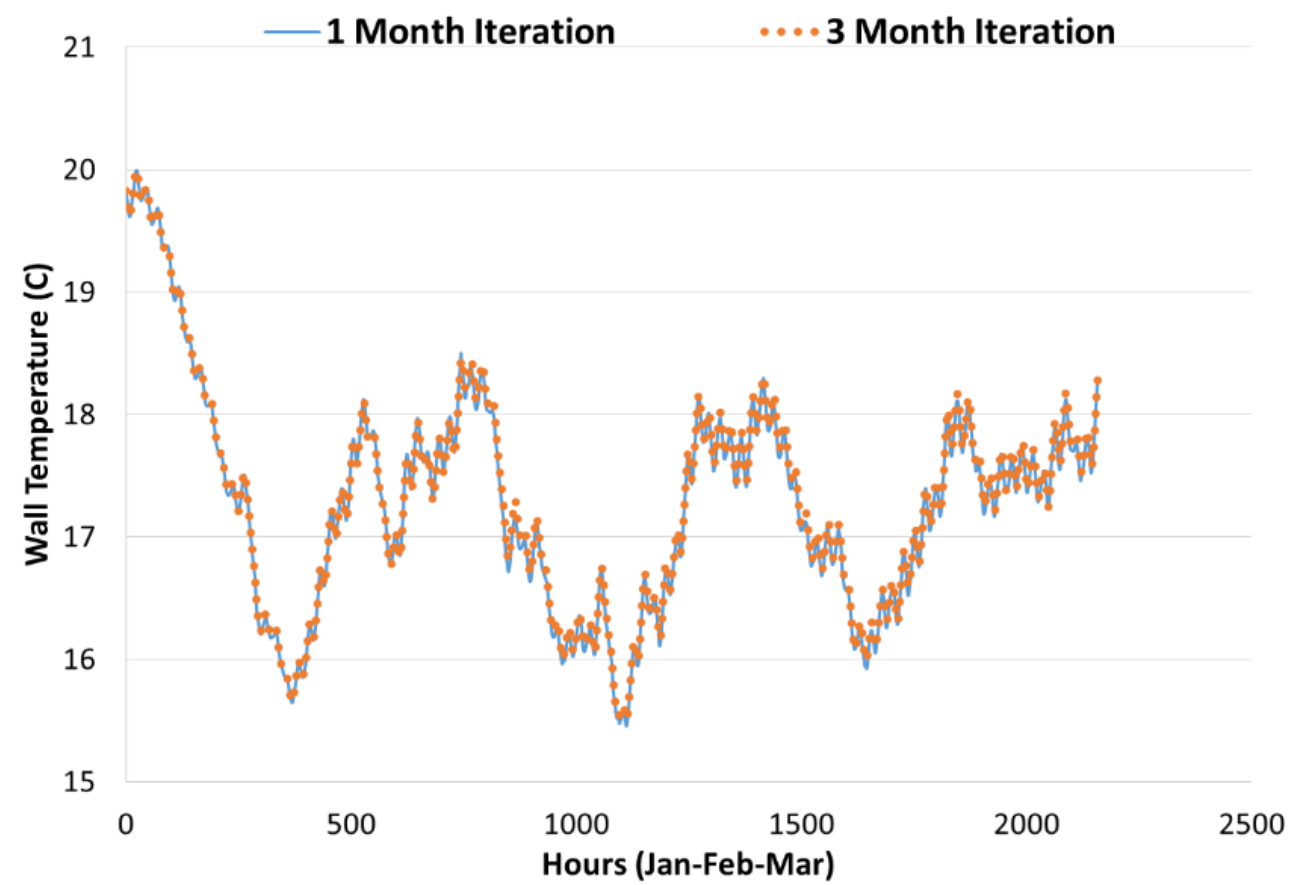

Figure 7. Comparison of outer tunnel wall temperature for the months of January, February, and March, using 1 month iterations, and 3 month iterations.

\section{Simulation Results and Discussion}

\subsection{Cooling Effect of the Ground Heat Exchangers}

A preliminary and rough estimation of the cooling effect of the vertical boreholes on the platform and tunnel temperatures is examined by imposing a radial boundary soil temperature around tunnel sections $\mathrm{B}$ and $\mathrm{C}$ in the $1 \mathrm{D}$ subway line model. A $10{ }^{\circ} \mathrm{C}$ constant temperature is assumed at 
a distance of $20 \mathrm{~cm}$ from the tunnel walls. The distance $20 \mathrm{~cm}$ is selected so that the boreholes are as a close as possible to the tunnel walls while allowing a soil clearance distance between the walls and the boreholes. This boundary layer emulates the soil temperatures that would result from heat extracted by the geothermal system. Note that the $10{ }^{\circ} \mathrm{C}$ boundary is ad-hoc and not used in the cosimulation model. It is used only in the $1 \mathrm{D}$ subway line model to estimate approximately the cooling effect of the boreholes close to the tunnels. This setup serves to roughly assess overall effect when temperature boundary lower than the background soil temperature is applied across proportions of the subway tunnel length $(1 \%, 25 \% 50 \%, 100 \%)$. The 1D subway line model is simulated for an entire year with a time step of $1 \mathrm{~min}$ for the scenarios having the $10{ }^{\circ} \mathrm{C}$ temperature boundary applied on $1 \%(15 \mathrm{~m}), 25 \%(375 \mathrm{~m}), 50 \%(750 \mathrm{~m})$ and $100 \%(1500 \mathrm{~m})$ of tunnel sections B and C, both westbound and eastbound.

Figure 9 compares the resulting tunnel and platform air temperatures with original temperatures (Central Line without ground heat exchangers). In Figure 8 and Figure 9, 'WB\%' means 'without boundary' and plots the temperature of those parts of the subway tunnel where the $10{ }^{\circ} \mathrm{C}$ boundary temperature is not applied (for example, the $10{ }^{\circ} \mathrm{C}$ boundary is not applied to parts of the tunnel that contain the platform). As expected, the influence of the $10^{\circ} \mathrm{C}$ soil boundary temperature on these parts of the tunnel depends on the overall proportion of the tunnel to which it is applied. When it is only applied to $1 \%(15 \mathrm{~m})$ of the tunnel, it has negligible effect on the tunnel and platform air temperatures. However, as this proportion is increased to $25 \%(375 \mathrm{~m}), 50 \%(750 \mathrm{~m})$ and $100 \%(1500 \mathrm{~m})$ the cooling effect is clearly noticed even in those parts of the tunnel where the $10{ }^{\circ} \mathrm{C}$ soil boundary temperature is not applied ('WB').

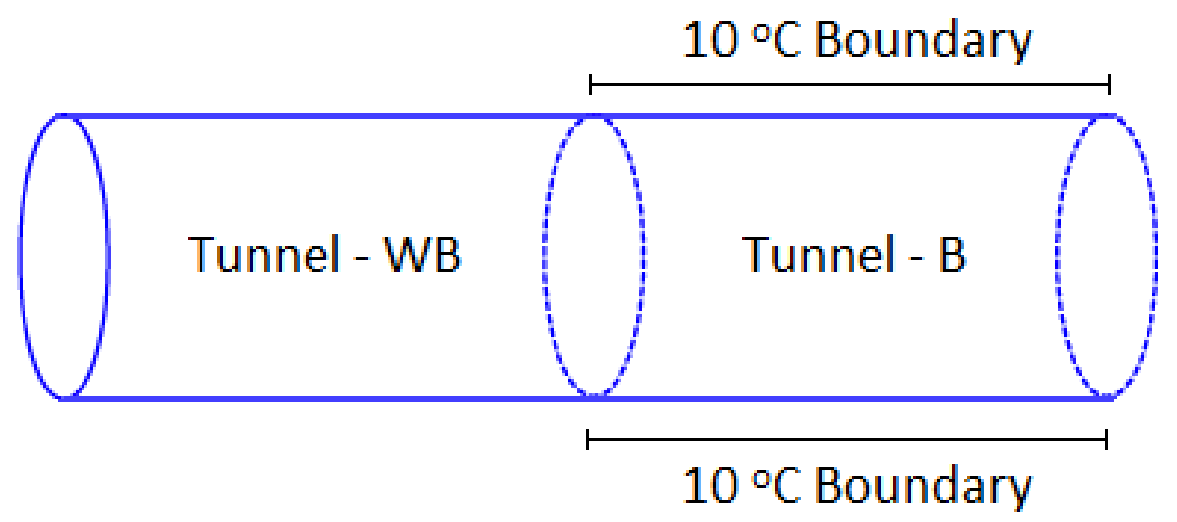

Figure 8. Schematic of tunnel section with $10^{\circ} \mathrm{C}$ boundary temperature (B) and without the boundary temperature (WB).

Naturally, the parts of the tunnel containing the $10{ }^{\circ} \mathrm{C}$ boundary will be even cooler since it will experience the highest heat transfer due the high temperature gradient created by the $10{ }^{\circ} \mathrm{C}$ temperature in the soil. This is shown when comparing temperatures of those parts of the tunnel to which the $10{ }^{\circ} \mathrm{C}$ soil boundary temperature is applied ('B\%'): The right-hand plot of (Figure 9) compares Tunnel WB-25\% with Tunnel B-25\%, and Tunnel WB-50\% with Tunnel B-50\%. The main point of these comparisons is that the 1D-3D co-simulations are necessary, as the cooling effect of the boreholes can be quite localised.

Figure 10 further demonstrates this by comparing the cooling effect (temperature decrease) of applying a $10{ }^{\circ} \mathrm{C}$ boundary soil temperature on $100 \%$ of the tunnels in the $1 \mathrm{D}$ model against the outputs of the co-simulation. It shows that the tunnel and platform temperatures drop by $8{ }^{\circ} \mathrm{C}$ and $9{ }^{\circ} \mathrm{C}$ respectively when the $1 \mathrm{D}$ model is simulated using the $10{ }^{\circ} \mathrm{C}$ boundary soil temperature across $100 \%$ of the tunnel length. However, as per the co-simulation results, the annual average 
soil temperature at $20 \mathrm{~cm}$ from the tunnel walls is $17{ }^{\circ} \mathrm{C}$, which is $7{ }^{\circ} \mathrm{C}$ higher than $10^{\circ} \mathrm{C}$. This shows that the assumption of using the $10{ }^{\circ} \mathrm{C}$ temperature boundary results in an exaggerated temperature drop in the tunnel and platform. The co-simulation outputs plotted in (Figure 10) also show that the borehole configuration described in Figure 3 results in decreasing the platform and tunnel air temperatures by $4.5^{\circ} \mathrm{C}$ and $5{ }^{\circ} \mathrm{C}$ respectively during summer conditions.
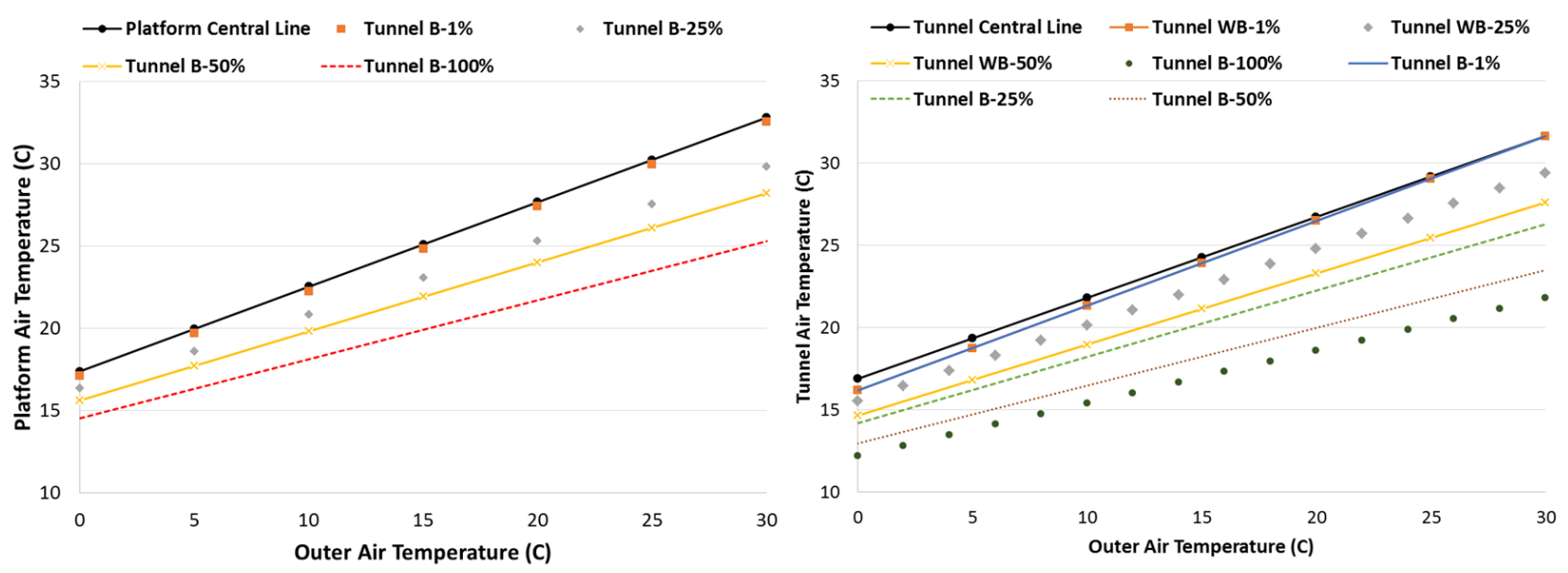

Figure 9. Original simulated Central Line platform (left) and tunnel (right) temperatures against $10{ }^{\circ} \mathrm{C}$ soil boundary temperature scenarios. 'WB\%' means 'without boundary' and plots the temperature of those parts of the subway tunnel where the $10{ }^{\circ} \mathrm{C}$ boundary temperature is not applied. 'B\%' means 'adjacent to boundary' and represents the temperature of those parts of the subway tunnel where the $10^{\circ} \mathrm{C}$ boundary temperature is applied.
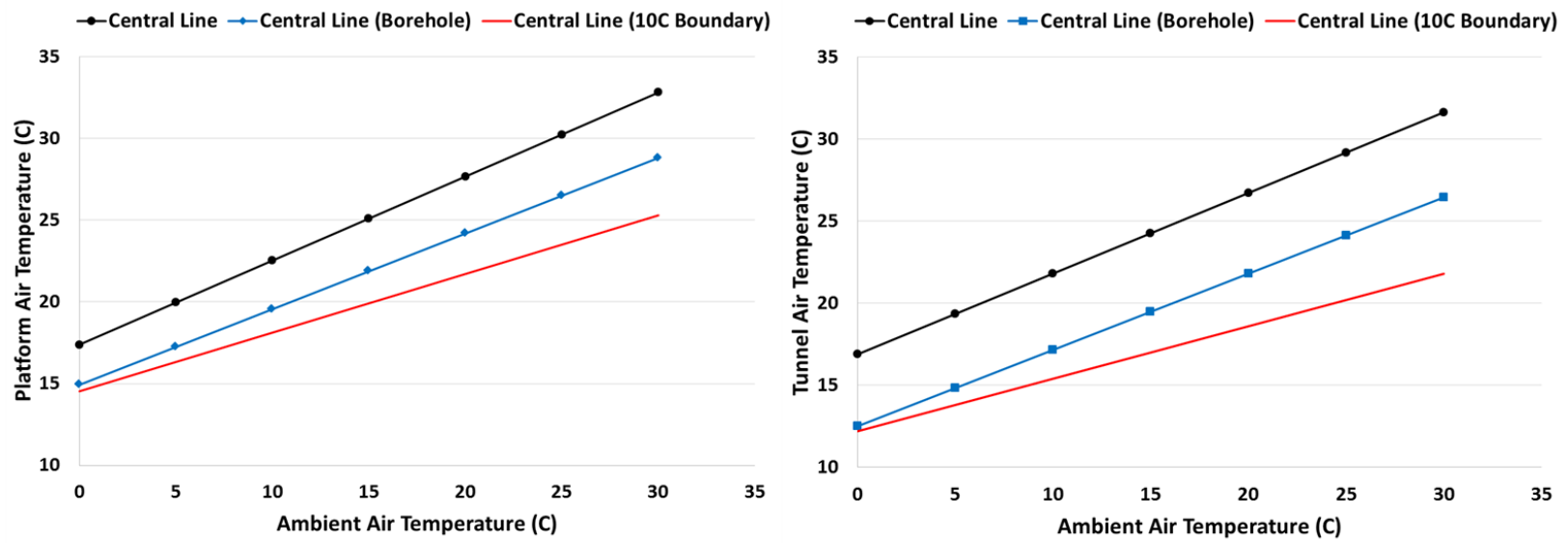

Figure 10. Original simulated Central Line platform (left) and tunnel (right) temperatures against co-simulation outputs and a $100 \% 10{ }^{\circ} \mathrm{C}$ soil boundary temperature.

\subsection{Heat Fluxes and Annual Extracted Heat}

This section discusses the heat extracted by the boreholes adjacent to the subway tunnels, as output by the co-simulation, and compares it against simulation outputs of a standard stand-alone borehole. In ground heat transfer problems it is standard to neglect the simulation outputs of first two years, as steady-periodic conditions take a number of years before being established. Figure 11 therefore shows the heat flux at the surface of the boreholes adjacent to the subway tunnel against the stand-alone borehole for the third simulation year. 
Figure 11 plots the transient surface heat flux developing at different vertical heights of a borehole adjacent to the tunnel. Negative heat flux indicates that the direction of heat transfer is inward the borehole surface. In Figure 11, heat flux at 'borehole $(0 \mathrm{~m}-9 \mathrm{~m})$ ' represents the borehole section from the height of the tunnel center to $9 \mathrm{~m}$ above and below the tunnels, 'borehole $(9 \mathrm{~m}-18 \mathrm{~m})$ ' is the borehole section between $9 \mathrm{~m}$ to $18 \mathrm{~m}$ above and below the tunnel center, and the same applies to 'borehole $(19 \mathrm{~m}$ to $50 \mathrm{~m})$ '. The three sections together constitute the entire borehole of $100 \mathrm{~m}$ length, and the average heat flux over the entire borehole is also plotted in Figure 11. Also included in the figure is the average heat flux at the surface of a similar standard stand-alone borehole (100 m long vertical closed loop heat exchanger). Plotting heat fluxes at different sections of the stand-alone borehole is not necessary, since the heat transfer is uniform over its entire length, except at the tips.

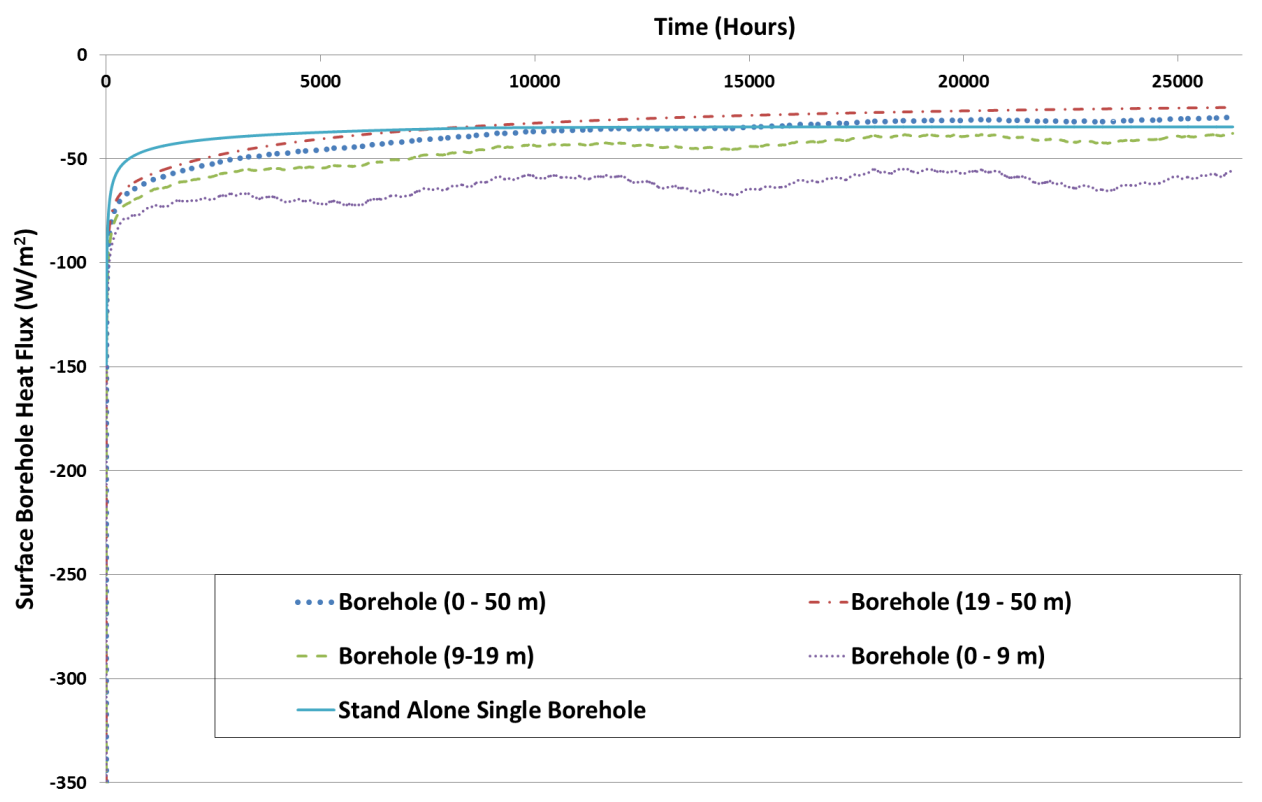

Figure 11. Heat flux at the surface of the boreholes adjacent to the subway tunnel compared against stand-alone borehole.

Figure 11 shows that the average heat flux of the borehole section adjacent to the subway tunnel fluctuates slightly due to the transient temperature profile of the tunnel walls. This is more explicit when the heat fluxes in different sections of the borehole are examined, where transient effects are most dominant near the tunnels at 'borehole $(0 \mathrm{~m}-9 \mathrm{~m})$ '. Figure 11 also shows that the heat transfer from the tunnels to the boreholes indeed occurs mostly within the first $18 \mathrm{~m}$ diameter (Figure 12). The borehole section near the tunnels $(0 \mathrm{~m}-9 \mathrm{~m})$ has the highest heat flux, which is almost $50 \%$ $\left(19 \mathrm{~W} / \mathrm{m}^{2}\right)$ more than the stand-alone borehole, because of the relatively high temperatures of the tunnels.

The average heat flux of the borehole adjacent to the subway tunnel is slightly less than that of the stand-alone borehole. This is due to thermal inference between the boreholes in the direction across the width of the tunnels (see Figure 13). Indeed, the thermal interference between the boreholes is also noticeable when observing that the transient heat extraction between 19-50 m of the borehole length is $13 \mathrm{~W} / \mathrm{m}^{2}$ less than that of the stand-alone borehole (see Figure 11): One would expect that, if the boreholes were spaced so as to not allow thermal interference, the heat extraction between 19-50 m of the borehole length would be almost identical to the stand-alone borehole, as the influence of the elevated subway tunnel temperatures is negligible at that distance. This compromise is necessary though, since to better cool the subway tunnels, the boreholes have to be placed as close as possible to them. At steady state, the average heat flux of the borehole adjacent 
to the tunnel is $8 \mathrm{~W} / \mathrm{m}^{2}$ less than that of the stand-alone borehole. The annual average heat flux of the borehole adjacent to the tunnel is $42 \mathrm{~W} / \mathrm{m}^{2}$, which is equivalent to $17.64 \mathrm{~W} / \mathrm{m}$ for every meter of the borehole. This value is close to the tabulated value of $20 \mathrm{~W} / \mathrm{m}$ in the Microgeneration Installation Standard for vertical boreholes (DECC 2011) with $0^{\circ} \mathrm{C}$ average fluid temperature, a diameter of $13 \mathrm{~cm}$, and surrounding background soil temperature of $14^{\circ} \mathrm{C}$, whilst operating for 7200 hours compared to our simulation (recall that we assume the boreholes to operate at all hours in the year).

In sum, the annual heat extracted by a single borehole adjacent to the tunnel is $9336 \mathrm{kWh}$, and in the stand-alone borehole it slightly increases by $9 \%$ to $10177 \mathrm{kWh}$. The heat from the tunnel per meter is $3100 \mathrm{kWh} / \mathrm{m}$. The average annual domestic heating demand in 2013 was $9300 \mathrm{kWh}$ (DECC 2013), so a single borehole could potentially supply an equivalent of one UK house (note though that we do not yet account for 'timing of demand versus supply' within this study).

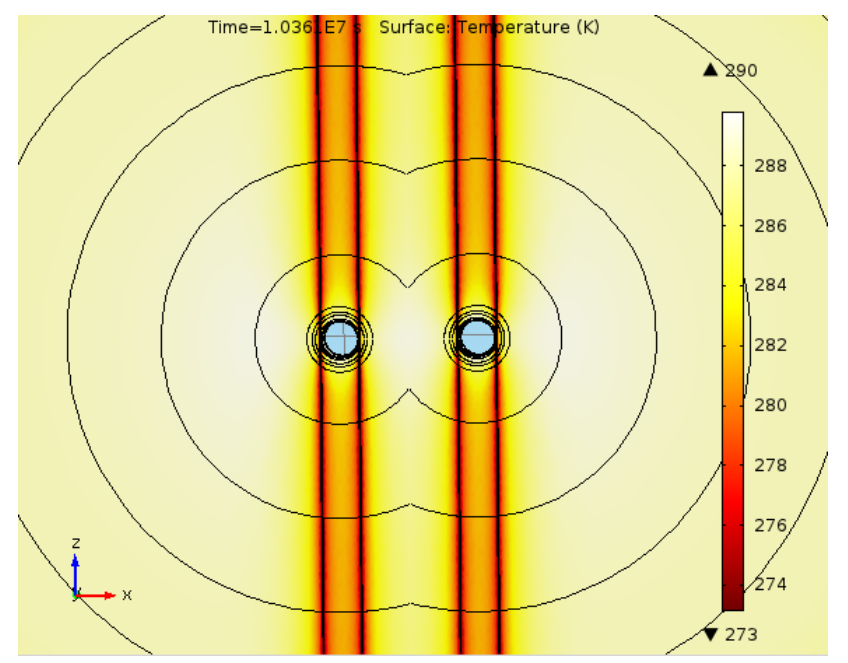

Figure 12. Cross sectional temperature distribution at the end of April.

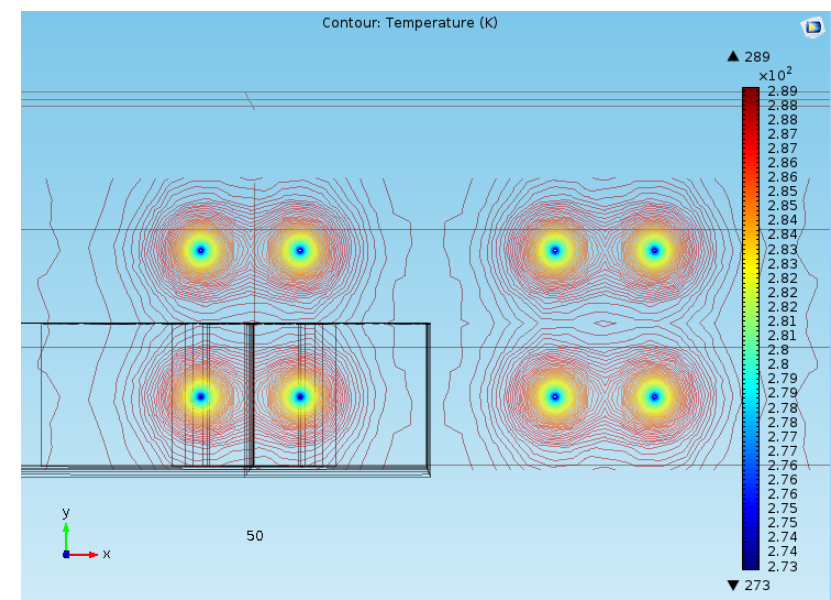

Figure 13. Top plane section (19m above tunnel centres) of the boreholes, temperature contour distribution at the end of April. 


\section{Simulation Scenarios}

\subsection{Position of Boreholes around the Subway Tunnel}

The locations of the boreholes are varied in order to assess whether there is a better arrangement that can compromise between heat extraction from the tunnels and the surrounding ground while minimizing thermal interference between the boreholes. Case A represents the base case simulated previously, where the distance between the boreholes across the tunnel sections is $4.16 \mathrm{~m}$, which is the closest possible to the tunnels (Figure 14). In Case B, the distance between the boreholes is increased to $6 \mathrm{~m}$, which is recommended by the Microgeneration Certification Scheme Standards (DECC 2011) to minimize thermal interference between the boreholes. Cases C and D have the same geometry of A and B respectively, except that they are not adjacent to a subway tunnel, making it possible to study the thermal interference of the boreholes without the influence of the subway tunnel acting as a heat source. In Case $\mathrm{E}$ the distance between the two line arrays of boreholes across is kept at $4.16 \mathrm{~m}$, but their arrangement is scattered such that the boreholes in one line are shifted by $3 \mathrm{~m}$, which is half the distance between two boreholes in the same line as seen in Figure 14, and there is no subway tunnel. The purpose of Case E is to test if this scattered arrangement would decrease thermal interference between the boreholes compared to case $\mathrm{C}$. These cases are summarised in Table 1.
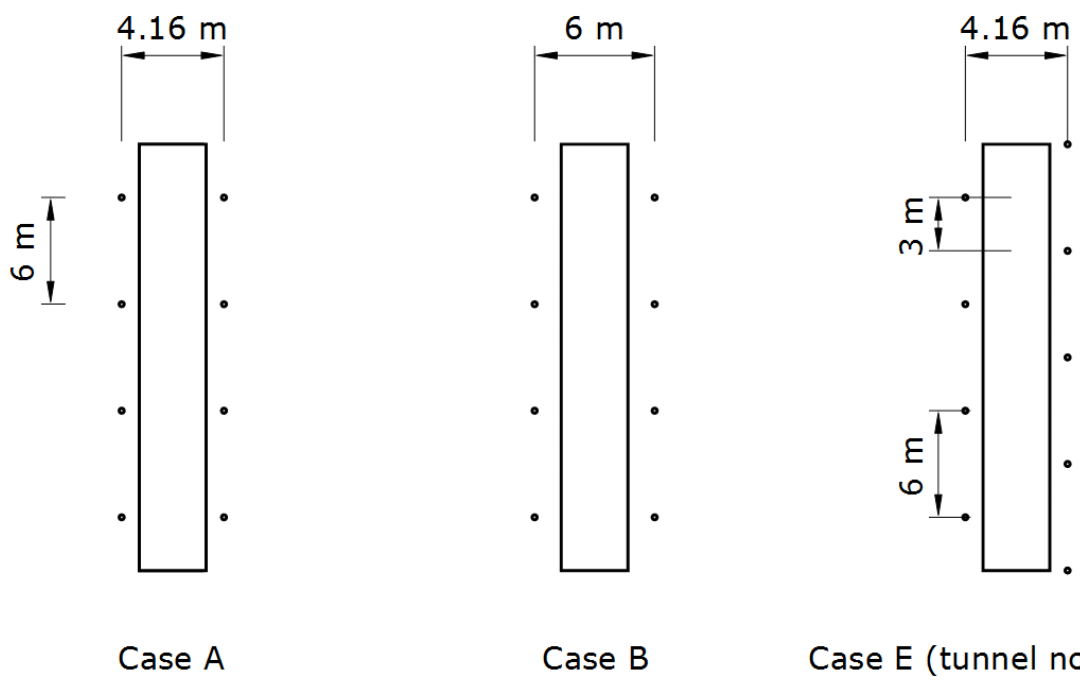

Case A

Case B

Case E (tunnel not included)

Figure 14. Schematic of cases A, B and E

Table 1. Description of the cases used to optimize the borehole design.

\begin{tabular}{lcl}
\hline Case & Borehole Distance $(\mathrm{m})$ & Description \\
\hline Case A & 4.16 & tunnel \\
Case B & 6 & tunnel \\
Case C & 4.16 & no tunnel \\
Case D & 6 & no tunnel \\
Case E & 4.16 & no tunnel - staggered borehole distribution \\
\hline
\end{tabular}

The surface heat fluxes for the 5 cases and the stand-alone borehole are compared over 3 simulation years in Figure 15. The amount of heat extracted from the tunnel surface for case A exceeds that of case B by $11 \mathrm{~W} / \mathrm{m}^{2}$ or $25 \%$, so the borehole distribution in case A is more effective at cooling the Tunnels than case B. The thermal interference between the boreholes is shown when comparing cases $\mathrm{C} \& \mathrm{D}$, where the heat flux in case $\mathrm{D}$ is $2.5 \mathrm{~W} / \mathrm{m}^{2}$ more than case $\mathrm{C}$ at the end of the year 3 (heat flux of case $\mathrm{C}$ and $\mathrm{E}$ is identical and therefore case $\mathrm{C}$ is not visible in the plot). 
Staggered borehole distribution produces no benefits, as seen when comparing cases C \& E, where their heat fluxes are almost identical. Case A is the most optimal arrangement for the boreholes around the tunnel, resulting in the highest heat extraction from the tunnel surfaces and consequently the most effective cooling effect in the underground's tunnels. However, case A does suffer from slight thermal interference between its boreholes leading to a decrease in borehole heat flux, which is compensated by the heat extracted from the tunnels.

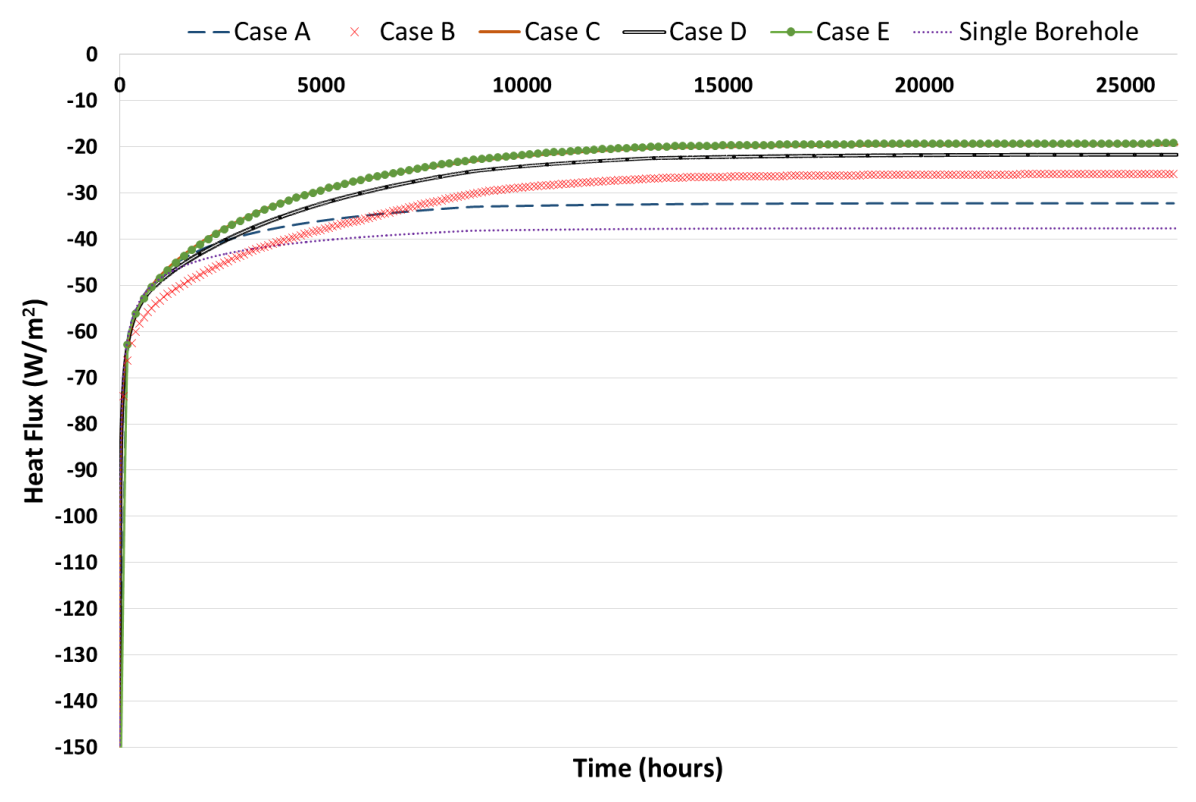

Figure 15. Comparison between Case A, Case B, Case C, Case D, Case E and single stand-alone borehole heat flux variations for 3 years of simulation.

\subsection{Partially Insulated Boreholes}

The heat demand of buildings is typically high in winter and low in summer. However, the London Underground requires cooling during summer conditions. This creates a paradox, because at a time when heat demand is low in the buildings above, the heat extraction from the tunnels should be at its maximum. Also, it is not feasible to have the boreholes extract heat all around the year, as that would lead to the cooling of the surrounding soil, and consequently a decrease in borehole performance. To tackle these two problems simultaneously, a double U borehole arrangement is considered (Figure 16). Each of the two $U$ tubes inside the borehole is insulated using refrigerant pipe insulation in the arrangement seen in Figure 16. This arrangement allows the borehole to operate in two modes across the year. During the winter period (including spring and autumn) the two U pipes will extract heat from the ground. During summer conditions the U pipe that is exposed to the tunnel, will keep extracting heat, while hot refrigerant is pumped in the second $\mathrm{U}$ pipe that is insulated next to the tunnel section, such that it will inject heat in the soil far away from the tunnel. In this manner, the boreholes could provide heating to the buildings during winter, and both cooling and heating to the buildings during summer. Also, by iterating operation modes between heating and cooling the heat balance between the heat extracted and injected in the soil can be maintained.

As a basic case the boreholes are assumed to run on 2 modes during the year, from October to April the boreholes are run in winter mode, only extracting heat. In summer mode (from May to September), the boreholes are both extracting heat near the tunnel and injecting heat far from the tunnel. It is also necessary to determine the length of the non-insulated U pipe sections that 


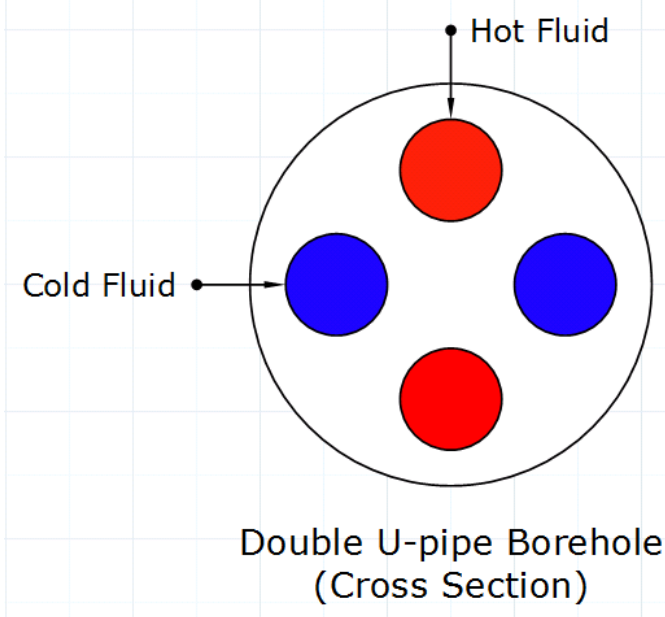

(Cross Section)

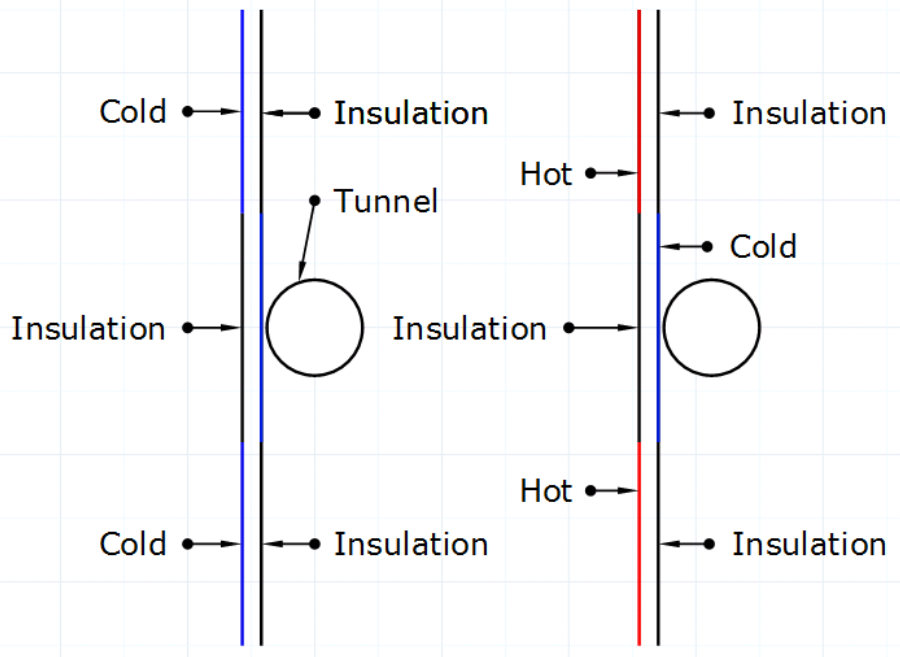

Winter Condition Summer Condition

Figure 16. Partially Insulated Borehole Cross-section design (left), and the variation of the insulated and non insulated sections operation modes between winter and summer(right).

would be sufficient for extracting heat from the tunnel. This is achieved by varying the dimension of the non-insulated $U$ pipe facing the tunnel such that the temperature of the soil, $20 \mathrm{~cm}$ away from the tunnel wall, output by the 3D model is equivalent to the temperature output by the base case (the base case being $100 \mathrm{~m}$ non-insulated borehole in heat extraction mode only). Thus, three cases are simulated, where the non-insulated U pipe facing the tunnel dimensions are $7 \mathrm{~m}, 18 \mathrm{~m}$, and $30 \mathrm{~m}$. These parts of the boreholes extract heat from the tunnels all around the year. Similar to before, the 1D Central Line and 3D borehole models are co-simulated, where the same borehole arrangement as that of Case $\mathrm{A}$ is used. The temperature of the borehole is $0^{\circ} \mathrm{C}$ when extracting heat and $30{ }^{\circ} \mathrm{C}$ when injecting heat.

Results show that the partially insulated boreholes with a dimension of $30 \mathrm{~m}$ will have a similar cooling effect to the original case, because they both yield the same outer tunnel wall temperatures, as seen in Figure 17 \& Figure 18. On the other hand, for the case of $7 \mathrm{~m}$ and $18 \mathrm{~m}$, the outer tunnel wall temperatures are influenced by the uninsulated sections of the boreholes far from the tunnel that alternate between heat extraction and heat rejection modes, such that the outer tunnel wall temperatures are higher. The temperatures are similar for all the cases at the beginning of the first year until the month of May (Month 4), where the temperatures start diverging from the original case. The temperature divergence increases for $7 \mathrm{~m}$ and $18 \mathrm{~m}$ as the upper and lower borehole sections switch from heat extraction and heat rejection between the months of May (Month 4) and September (Month 9), and then decreases as the entire borehole switches back to operating in heating extraction only, where the maximum temperature difference between $10 \mathrm{~m}$ and $18 \mathrm{~m}$ is around $0.35{ }^{\circ} \mathrm{C}$ during the month of September. Therefore, the cooling of the tunnel would not be effected by the switching of the $\mathrm{U}$ pipe between heat extraction and rejection modes during summer, because the $\mathrm{U}$ pipe section operating constantly in heat extraction mode creates a cooling bubble around the tunnel that shields it from the heat injected in the soil by the other $\mathrm{U}$ pipe section as seen in Figure 18.

The surface heat fluxes of the over the period of 3 years are shown in Figure 19, where $0 \mathrm{~m}-15$ $\mathrm{m}$ represents the $30 \mathrm{~m}$ non-insulated section next to the tunnels, and the $15 \mathrm{~m}-50 \mathrm{~m}$ the borehole section that switches between heating and cooling modes far away from the tunnel. Figure 19 shows that the heat fluxes in both the $0 \mathrm{~m}-15 \mathrm{~m}$, and $15 \mathrm{~m}-50 \mathrm{~m}$ become consistent in performance over the last 2 years, where the variation in the heat fluxes in $0 \mathrm{~m}-15 \mathrm{~m}$ section is dependent on the outer tunnel wall temperatures. In Table 2 the total amount of heat extracted in each section of 


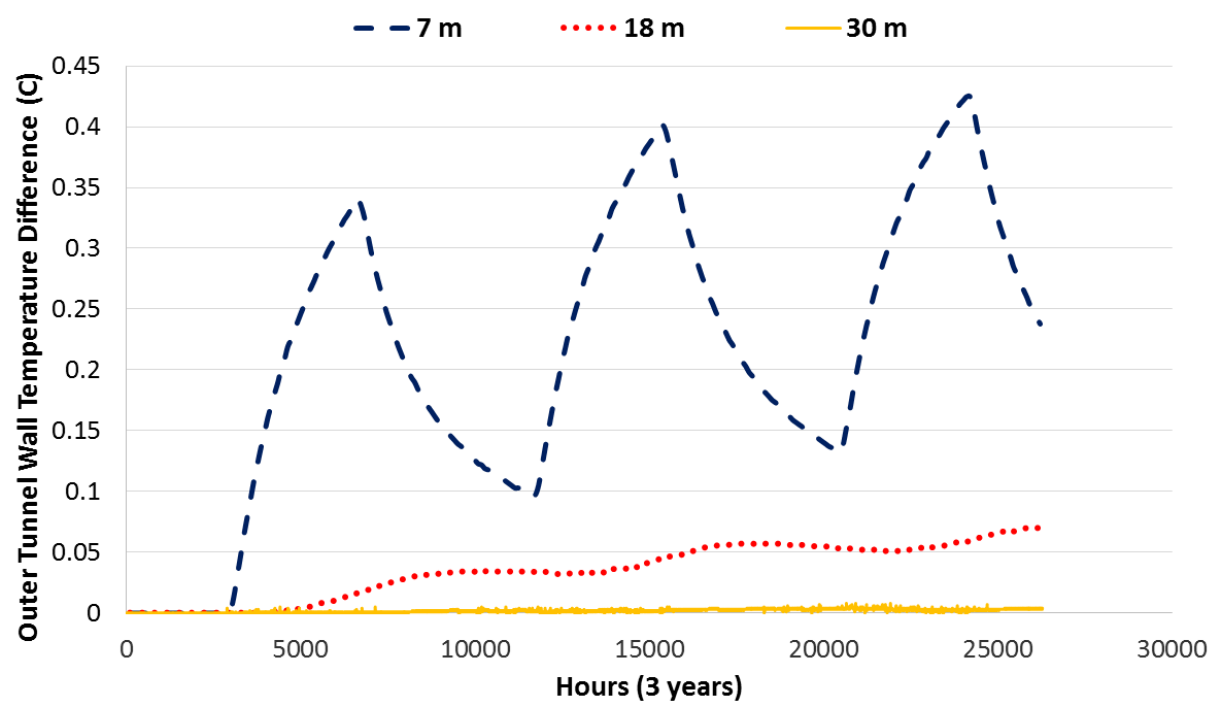

Figure 17. Outer tunnel wall temperature difference between the completely non insulated borehole, and partially insulated borehole having non-insulated sections facing the tunnels $7 \mathrm{~m}, 18 \mathrm{~m} \& 30 \mathrm{~m}$ lengths for a simulation period of 3 years.

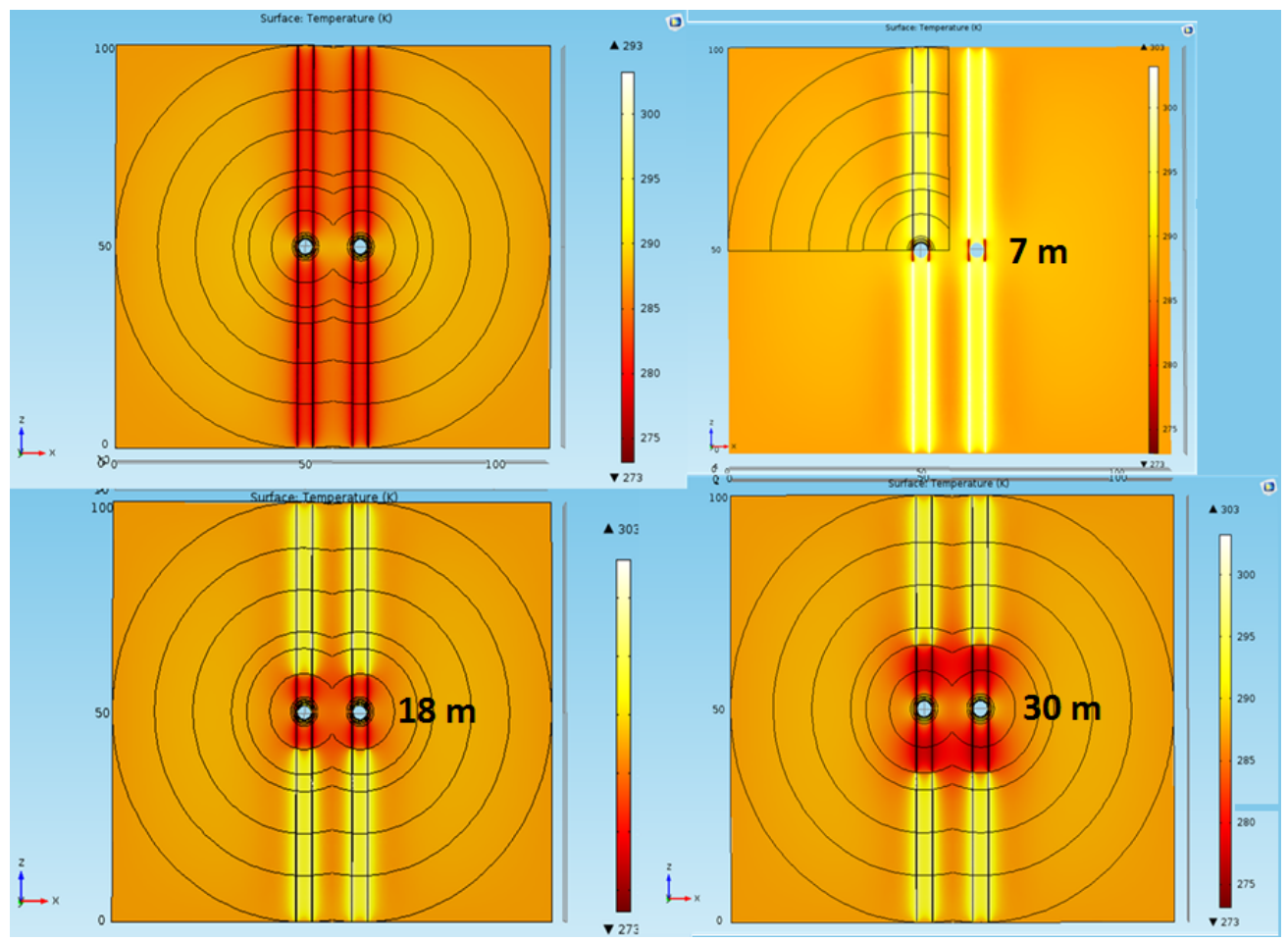

Figure 18. Cross sectional borehole temperature distribution at the end of September in the third year for a completely non insulated borehole (top left), and partially insulated borehole having non-insulated sections facing the tunnels $7 \mathrm{~m}, 18 \mathrm{~m} \& 30$ m lengths.

the partially insulated boreholes for the third year is listed, and compared to the original case.

Using surface heat flux integration over the borehole surfaces, the amount of heat extracted and injected in the soil is calculated for both the non-insulated borehole and the partially insulated borehole for the third year of operation (Table 2). The value calculated is for half of the borehole $(0 \mathrm{~m}-50 \mathrm{~m})$, because of the symmetry used in the 3D FEM model. Over the third year the noninsulated borehole extracts $4668 \mathrm{kWh}$ of heat, which is $9336 \mathrm{kWh}$ for the entire borehole. The partially insulated borehole extracts $2271 \mathrm{kWh}$ for the entire year for its $(0 \mathrm{~m}-15 \mathrm{~m})$ section next to the tunnel, and for the $15 \mathrm{~m}-50 \mathrm{~m}$ section it extracts $1570 \mathrm{kWh}$ from January to April, and 


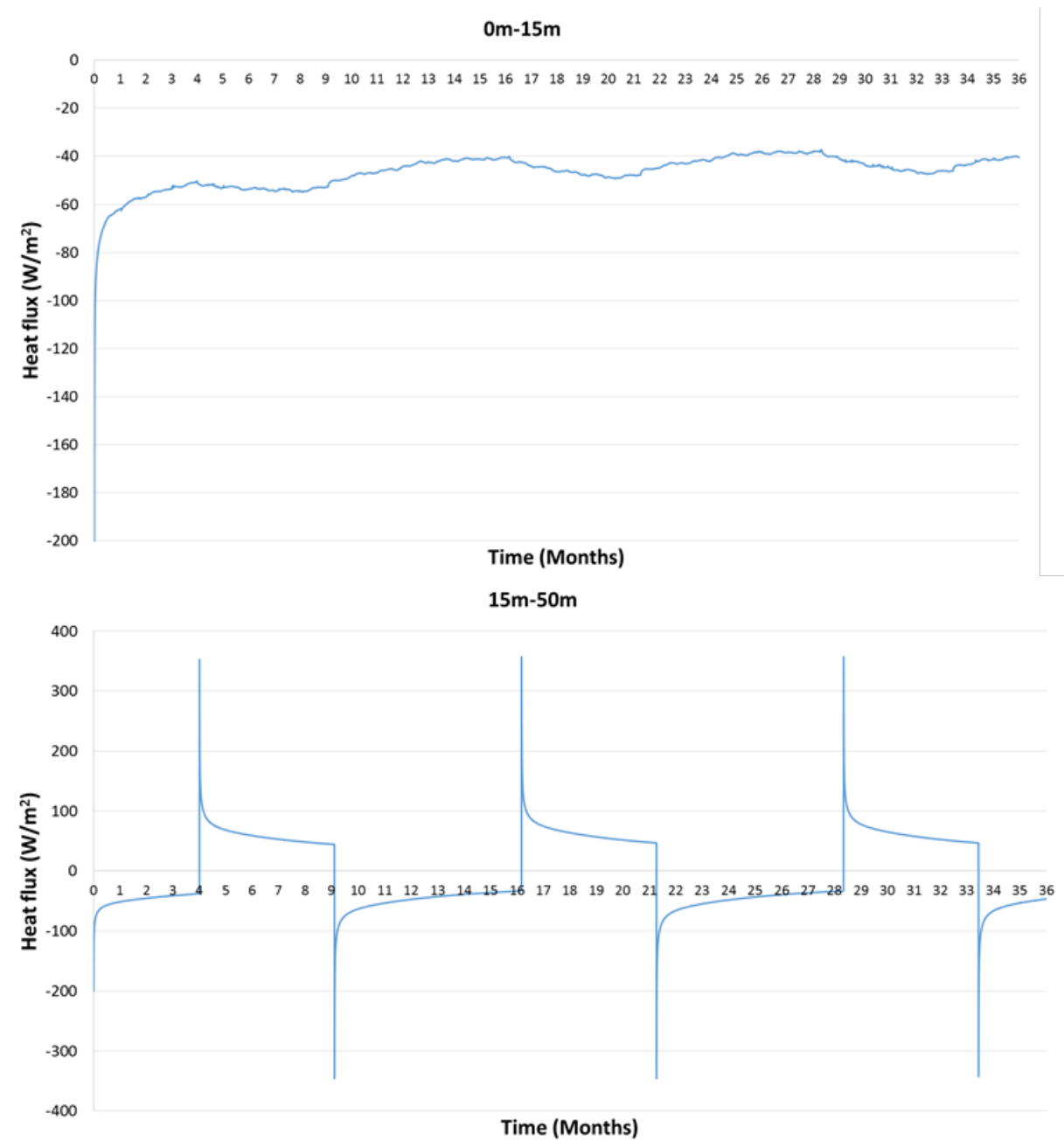

Figure 19. Partially insulated borehole surface heat flux for section (0m-15m) (upper figure) near the tunnel and (15m-50m) far away from the tunnel for a period of 3 year simulations.

$1861 \mathrm{kWh}$ from October to December. In total the partially insulated borehole extracts $5702 \mathrm{kWh}$ over the entire year, which is $11404 \mathrm{kWh}$ for the entire borehole. The partially insulated borehole $(15 \mathrm{~m}-50 \mathrm{~m})$ section injects $3350 \mathrm{kWh}$ into the soil from May to September, which is $6700 \mathrm{kWh}$ for the entire borehole which could be used to cool the buildings above the tunnels.

It is worth to note that the total amount of heat extracted from the ground by the $15 \mathrm{~m}-50 \mathrm{~m}$ section of the boreholes is approximately equal to the amount of heat injected back when operating in cooling mode, which indicates that the ground achieves a thermal balance throughout the year. Table 2 shows that the amount of heat extracted by the $15 \mathrm{~m}-50 \mathrm{~m}$ section of the borehole, which operates 7 month annually (January - April and October - December), is $(1570+1861) \mathrm{kWh} \mathrm{x}$ $2=3431 \mathrm{kWh}$. The amount of heat injected into the soil by this borehole section $(15 \mathrm{~m}-50 \mathrm{~m})$, which operates 5 month a year in cooling mode (May - September), is equal to $3350 \mathrm{kWh} \times 2=$ $6700 \mathrm{kWh}$. The difference between the amount of heat extracted and injected within this section is therefore $162 \mathrm{kWh}$. This difference is small compared to the total magnitude of the heat exchanged. This will not effect the cooling effect in the tunnel since the partially insulated borehole section $(0$ $\mathrm{m}-15 \mathrm{~m}$ ) always operates on extracting heat in the proximity of the tunnel all around the year, as has been shown previously in Figure 17.

Since the annual average UK house heating and water heating demand is $9300 \mathrm{kWh}$, a single noninsulated borehole can provide heating for $1 \mathrm{UK}$ house hold, while the partially insulated borehole can provide heating for 1.25 UK households and an addition of $6700 \mathrm{kWh}$ of cooling during summer 
Table 2. Annual heat extracted and cooling potential for a non-insulated and partially insulated borehole.

\begin{tabular}{|c|c|c|c|c|c|}
\hline Borehole & $\begin{array}{c}\text { Total Heat Extracted } \\
\text { All Year }(\mathrm{kWh}) \\
(0 \mathrm{~m}-15 \mathrm{~m})\end{array}$ & $\begin{array}{c}\text { Total Heat Extracted } \\
\text { Jan-Apr }(\mathrm{kWh}) \\
(15 \mathrm{~m}-50 \mathrm{~m})\end{array}$ & $\begin{array}{c}\text { Total Heat Extracted } \\
\text { Oct-Dec }(\mathrm{kWh}) \\
(15 \mathrm{~m}-50 \mathrm{~m})\end{array}$ & $\begin{array}{c}\text { Total Cooling } \\
\text { May-Sept (Kwh) } \\
(15 \mathrm{~m}-50 \mathrm{~m})\end{array}$ & $\begin{array}{l}\text { Total Heat Extracted } \\
\text { All Year }(\mathrm{kWh})\end{array}$ \\
\hline Partially Insulated Borehole & -2271 & -1570 & -1861 & 3350 & -5702 \\
\hline Non Insulated Borehole & - & - & - & - & -4668 \\
\hline
\end{tabular}

conditions.

Non Insulated Borehole

(a)

(1)

(1) 


\section{Comparison with heating demand above ground}

Results of the previous section have shown a constant temperature drop of $4.5^{\circ} \mathrm{C}$ and $4{ }^{\circ} \mathrm{C}$ in the tunnel and platform temperatures respectively, assuming the GSHP system operates throughout the year. This section presents rough estimates of heat extracted from the tunnels compared to the heating demand of the buildings located above ground, within the vicinity of the tunnels.

As an illustrative case, a section of the Central Line covering 6 stations is considered. The Central Line passes under Bayswater Road next to Hyde Park, and Oxford Street, covering $4.8 \mathrm{Km}$ of tunnels. There are 62 blocks of buildings on both sides of the road and above the subway tunnel within this area. The building blocks are grouped into 31 building clusters, where the clusters are the building blocks on the right and left sides of the road under which the Central Line tunnels are located. These are numbered from 1 to 31 in Figure 20. The building type composition of each of the clusters by area is shown in Figure 21. The 31 clusters contain a total of 5335 buildings. Hourly heating demand per building within the clusters shown in Figure were obtained from the estimates of Zhang, Choudhary, and Soga (2015).

As per (Zhang, Choudhary, and Soga 2015), the total simulated heat demand for the 31 clusters is $162^{6} \mathrm{kWh}$, and the total area of the 31 clusters is $1.37 \times 10^{6} \mathrm{~m}^{2}$. This corresponds to $118 \mathrm{kWh} / \mathrm{m}^{2}$ on an average. The heat demand of each of the dominant building types in the 31 clusters is summed and normalized by their area in Table 3 . The building types listed in Table 3 constitute $97 \%$ of the area, and $95 \%$ of the total annual heat demand of the entire buildings in the 31 clusters. These values were found to be within the ranges of the typical heating consumption found in (CIBSE 2012).

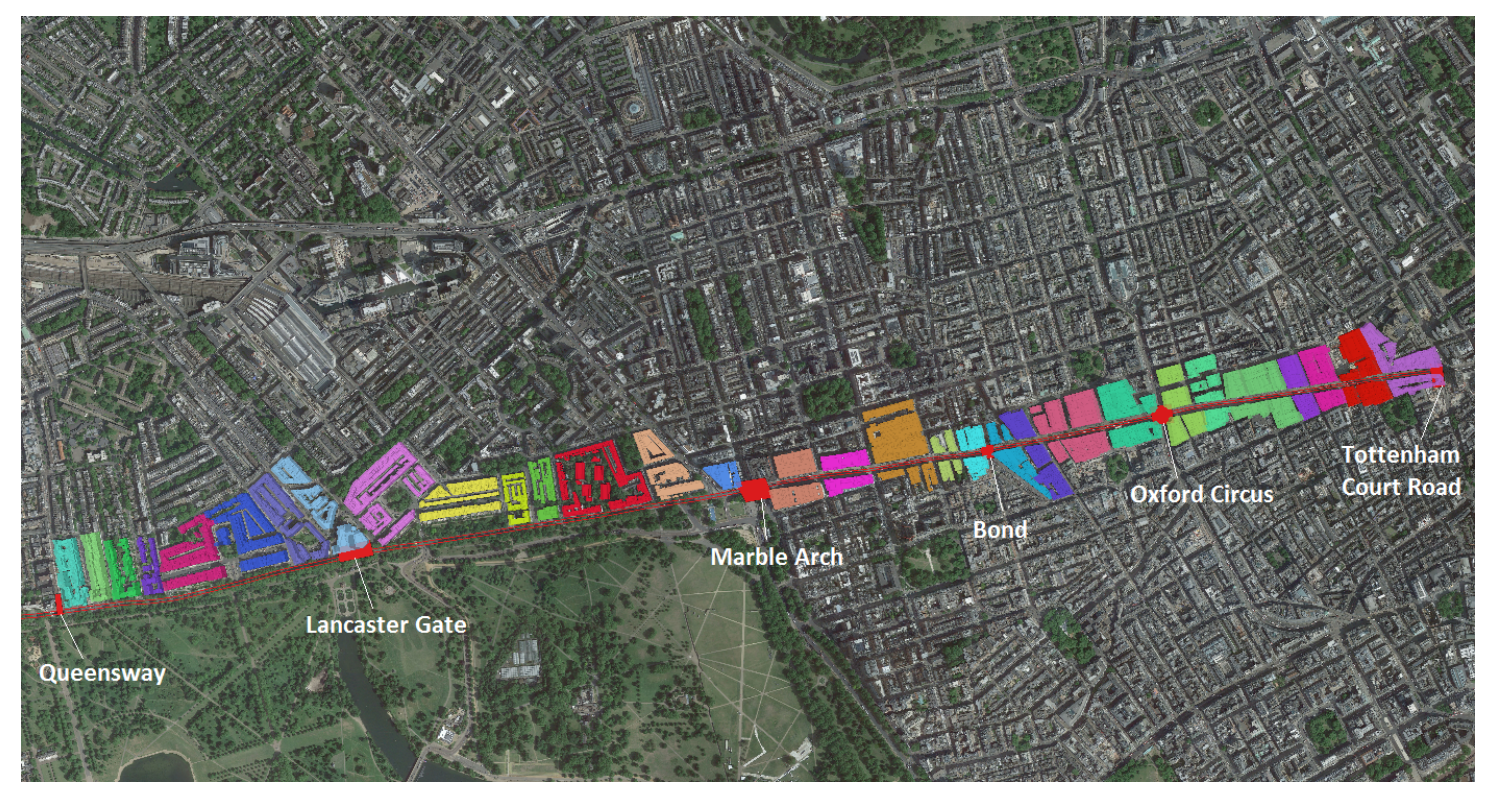

Figure 20. Map showing a section of the Central Line, and the 31 building clusters surrounding the tunnels, where each cluster is marked by a distinct color, and they are numbered from 1 to 31 from the left to the right side of the map.

The ground heat exchangers or the boreholes are assumed to be placed on the sides of the tunnels and not the platforms, following the configuration shown in Figure 3. Since the platforms are 140 $\mathrm{m}$ long, and the total length of the tunnels between the 6 stations is $4.8 \mathrm{Km}$. The length of the tunnels, platforms excluded, is $3910 \mathrm{~m}$, which can accommodate 2600 boreholes if we consider there are 4 boreholes every $6 \mathrm{~m}, 2$ for the westbound and 2 for the east bound tunnels. The length of 


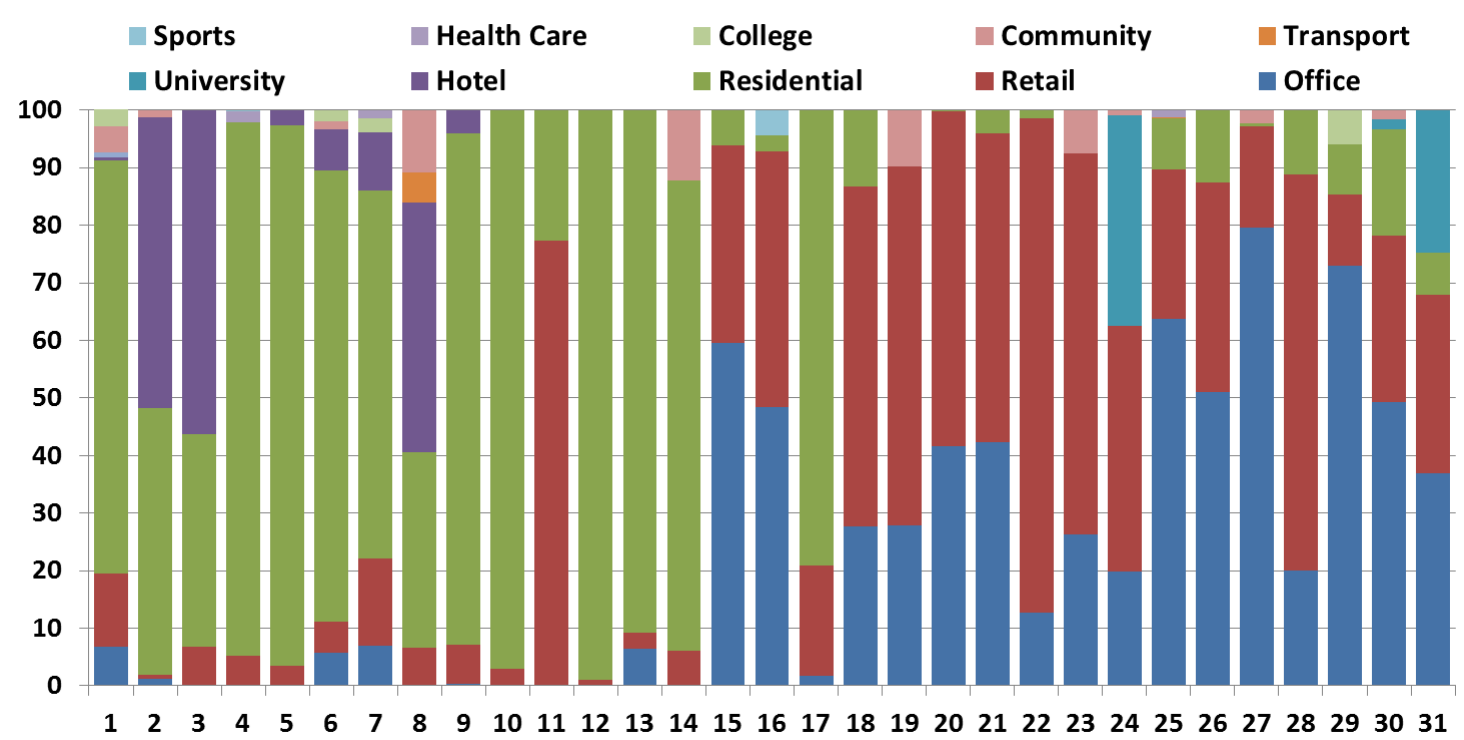

Figure 21. Building type percentage distribution by area of each of the 31 building clusters.

Table 3. The Building clusters total annual heat demand by building type per $\mathrm{m}^{2}$ compared to their typical energy consumption bechmark from from the CIBSE Guide F Range (CIBSE 2012).

\begin{tabular}{|l|c|c|c|c|c|}
\hline Building Type Affices & Residential & University & Hotels \\
\hline $\begin{array}{l}\text { Total Annual Heat Demand per } \\
\text { Building Type (MWh) }\end{array}$ & 30199 & 48222 & 38937 & 7128 & 29240 \\
\hline $\begin{array}{l}\text { Total Building Type Area (m² } \\
1000 \text { 's) }\end{array}$ & 407 & 315 & 649 & 31 & 79.9 \\
\hline $\begin{array}{l}\text { Annual Heat Demand per Area } \\
\left(\mathrm{kWh} / \mathrm{m}^{2}\right)\end{array}$ & 113 & 165 & 70 & 390 & 382 \\
\hline CIBSE Guide F Range (kWh/m $\left.{ }^{2}\right)$ & $0-249$ & $151-210$ & $45-200$ & $120-600$ & $360-460$ \\
\hline
\end{tabular}

each borehole is fixed to be $15 \mathrm{~m}$ below the tunnels, as the main objective is to cool the tunnel environment. A schematic of the depth of the station platforms, the vertical borehole depth, and the tunnel distance between the stations is shown in Figure 22. The vertical borehole depth is fixed between two stations. For example in Figure 22 : Queensway is $30.1 \mathrm{~m}$ deep and Lancaster Gate is $27.5 \mathrm{~m}$ deep. The tunnels between these two stations will vary between the depth of $30.1 \mathrm{~m}$ and $27.5 \mathrm{~m}$. Since Queensway is deeper than Lancaster Gate, the depth of the boreholes in the tunnels between them is calculated as the depth of Queensway $(30.1 \mathrm{~m}$ ) plus $15 \mathrm{~m}$ which equals to $45.1 \mathrm{~m}$.

Since the temperature drop in the tunnel environment is similar if the boreholes are $15 \mathrm{~m}$ or longer below and above the tunnel, it is reasonable to use the outer tunnel wall temperatures obtained from the simulations of $100 \mathrm{~m}$ deep borehole described in section 2.3 (shown in Figure 23 for the 3rd simulation year). The 5 distinctive borehole depths are thus simulated using the FEM model, to determine the amount of heat extracted by each of the borehole length. The heat extracted from the vertical boreholes are summed along the tunnels bordering each of the building clusters. This is done by multiplying the annual amount of heat extracted by each of the boreholes length with the number of boreholes present between each of the 6 stations (4). The COP of the GSHP is assumed to be 3.3, which is a common typical design value for vertical closed loop GSHP systems (Kavanaugh and Rafferty 1997).

The total monthly heat extracted from the boreholes is compared to the total monthly heat demand of the 31 building clusters combined on the sides of the Central Line in Figure 24 \& Table 5. During the winter months (January, February and December) the vertical boreholes are able to cover $4.5 \%$ of the total building clusters heat demand. During summer months (June, 


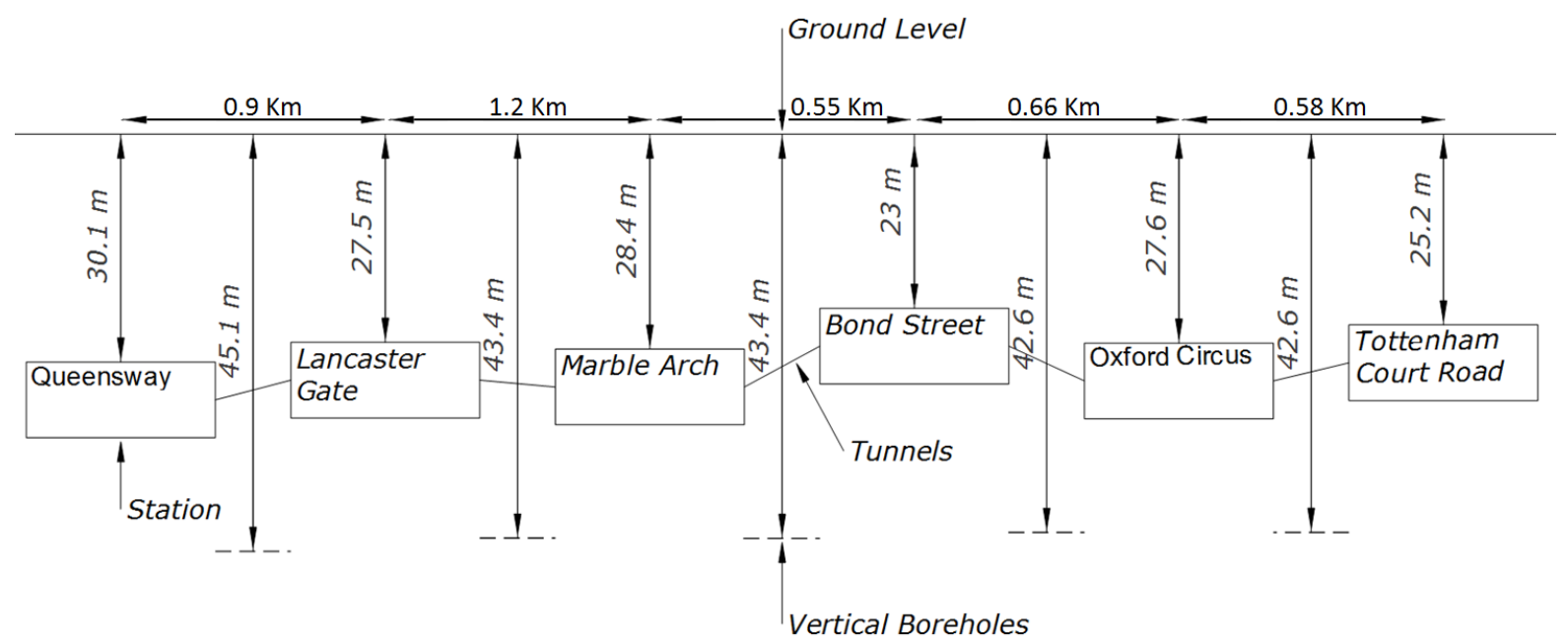

Figure 22. Station, tunnel, and vertical borehole depths \& tunnel distances between Queensway and Tottenham Court Road stations along the Central Line.

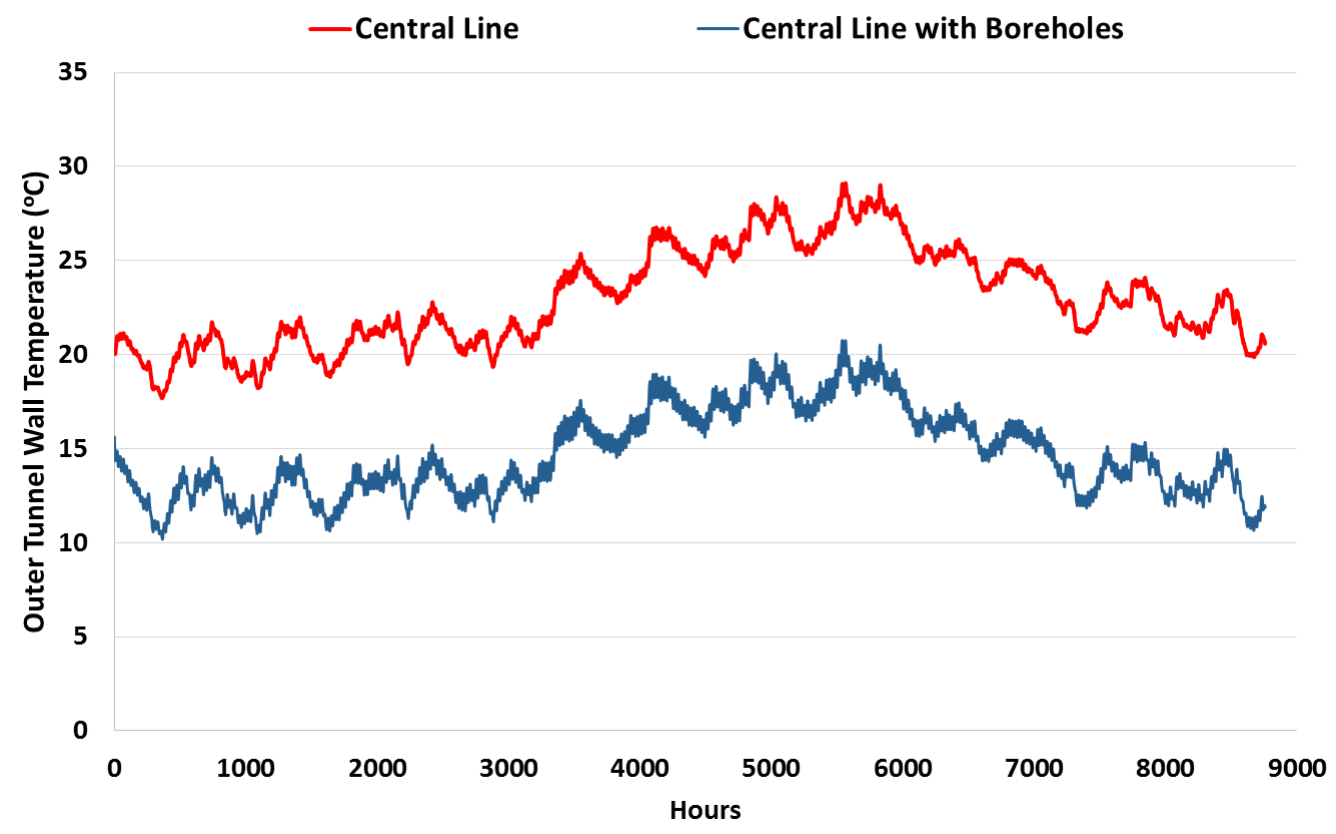

Figure 23. Outer tunnel wall temperatures for the Central Line model after three years of simulation for two cases: Tunnels Without Boreholes and Tunnels with Boreholes.

July and August) the boreholes can meet a higher percentage of the building heat demand as in June (33.4\%), July (74\%) and August (49.2\%). The building heat demand in the month of July is attributed to hot water demand (roughly $13 \mathrm{kWh} / \mathrm{m}^{2}$, which is close to the annual average water heat demand of $11 \mathrm{kWh} / \mathrm{m}^{2}$ for buildings of mixed use according to (DECC 2013)). The heat demand per unit area for the residential building types for the month of July is $17 \mathrm{kWh} / \mathrm{m}^{2}$, which is within the range of residential water heat demand which ranges between $13 \mathrm{kWh} / \mathrm{m}^{2}-25$ $\mathrm{kWh} / \mathrm{m}^{2}$ (Burzynski et al. 2011). The amount of heat extracted by the boreholes varies throughout the year, where it is minimum during the month of January $1050 \mathrm{MWh}$ and maximum in the month of July 1295 MWh as a result of variations in the Central Line tunnel temperatures. The Central Line tunnels act as heat sources for the vertical boreholes, which provide a consistency with the amount of heat extracted throughout the year. The vertical boreholes cover a portion of the 31 clusters heat demand annually, where it covers the most for cluster $10(29 \%)$ and least for cluster 
Table 4. The annual heat $(\mathrm{kWh})$ extracted from each borehole length $(\mathrm{m})$, and the total amount of heat extracted $(\mathrm{kWh})$ between each of the tunnel sections between the 6 stations in the Central Line.

\begin{tabular}{|l|l|l|l|l|}
\hline Borehole Length $(\mathrm{m})$ & $\begin{array}{l}\text { Annual Heat Ex- } \\
\text { tracted per Bore- } \\
\text { hole (kWh) }\end{array}$ & Clusters & Number of Boreholes & $\begin{array}{l}\text { Annual Heat Ex- } \\
\text { tracted Between } \\
\text { Stations (MWh) }\end{array}$ \\
\hline 45.1 & 5454 & $1-9$ & 708 & 4.2 \\
\hline 43.4 & 5352 & $10-15$ & 632 & 3.4 \\
\hline 43.4 & 5352 & $16-20$ & 460 & 2.5 \\
\hline 42.6 & 5304 & $21-24$ & 320 & 1.7 \\
\hline 42.6 & 5304 & $25-31$ & 492 & 2.6 \\
\hline
\end{tabular}

$16(3.2 \%)$ as seen in Figure 25 and Figure 26.

The total annual amount of heat the boreholes, which have an averaged length of $43.6 \mathrm{~m}$, can provide between the 6 stations is $14.3 \times 10^{6} \mathrm{kWh}$ compared to $24.2 \times 10^{6} \mathrm{kWh}$ if the boreholes were $100 \mathrm{~m}$ long. Thus, adjusting the borehole length to $15 \mathrm{~m}$ below the tunnels results in a more efficient heat extraction compared per borehole length since a larger portion of the boreholes is closer to the tunnels. Since the COP of the heat pumps is 3.3 , the heat pumps would consume $4.33 \times 10^{6} \mathrm{kWh}$ of electricity. This would emit the equivalent of 1705 tons of $\mathrm{CO} 2$, since the carbon emission foot print of UK electricity production is $0.394 \mathrm{Kg} \mathrm{CO}_{2} / \mathrm{kWh}$ (DECC 2015). Assuming that the buildings currently utilize gas boilers for their heating which have a median efficiency of $96 \%$ (Garber, Choudhary, and Soga 2013), so it would take $14.9 \times 10^{6} \mathrm{kWh}$ worth of gas combustion to provide an equivalent amount of heating to the vertical boreholes. This would emit the equivalent of 2772 tons of $\mathrm{CO}_{2}$, since the carbon foot print of gas combustion in boilers is $0.194 \mathrm{Kg} \mathrm{CO}_{2} / \mathrm{kWh}$ (Garber, Choudhary, and Soga 2013). Consequently, retrofitting the tunnels with verticals boreholes would result in reducing building heating carbon emissions by 1067 tons of $\mathrm{CO}_{2}$ annually.

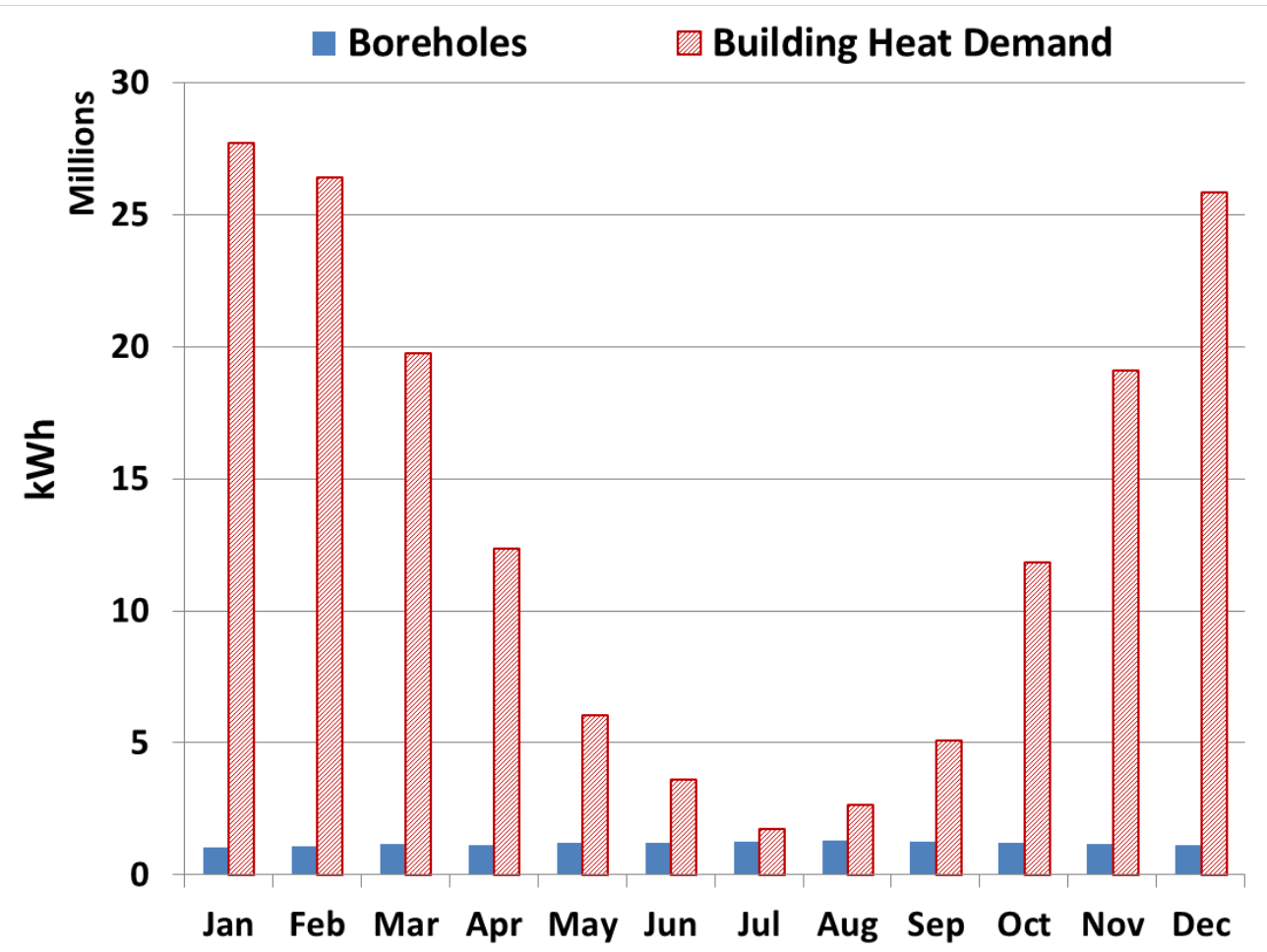

Figure 24. Building clusters total monthly heat demand $(\mathrm{kWh})$ in millions compared to the heat extracted from the vertical boreholes in the Central Line. 
Table 5. Building clusters total monthly heat demand compared to the heat extracted from the vertical boreholes in the Central Line in percentage.

\begin{tabular}{|l|c|c|c|c|c|c|c|c|c|c|c|c|}
\hline Month & Jan & Feb & Mar & Apr & May & Jun & Jul & Aug & Sep & Oct & Nov & Dec \\
\hline Head Demand (\%) & 4.5 & 4.1 & 6 & 9 & 20 & 33.4 & 74 & 49.2 & 24.5 & 10.3 & 6.1 & 4.4 \\
\hline
\end{tabular}

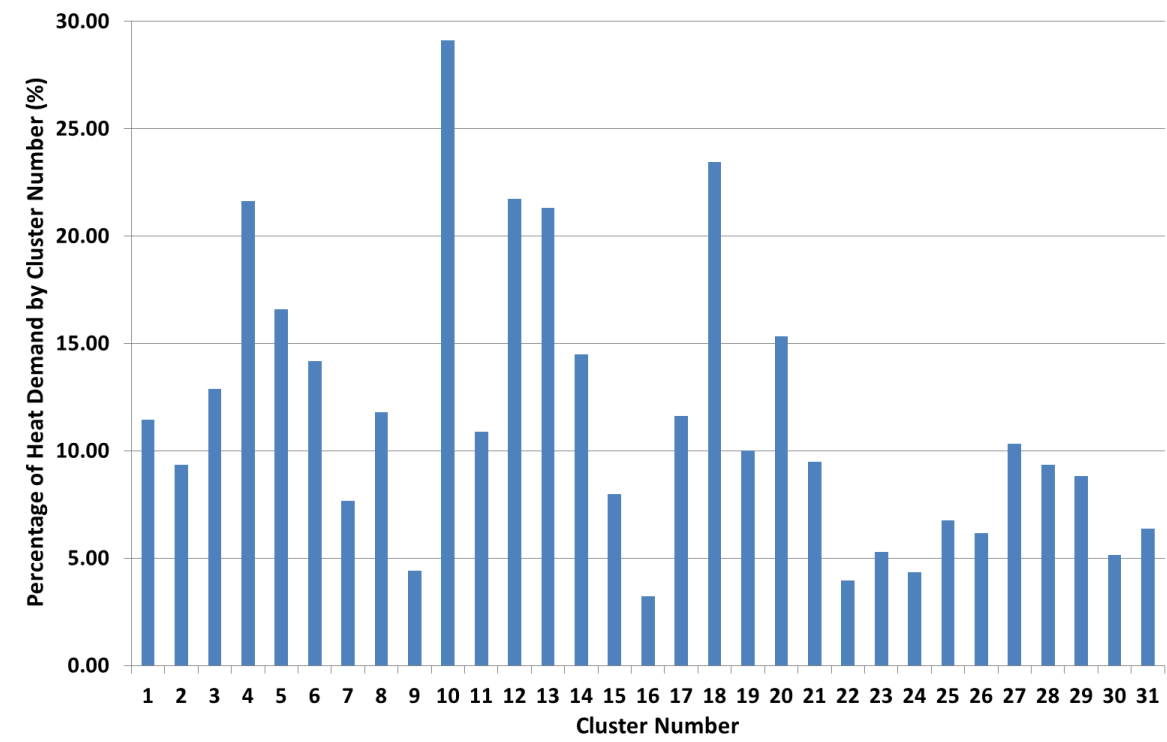

Figure 25. Building clusters annual heat demand compared to the heat extracted from the vertical boreholes in the Central Line in percentage.

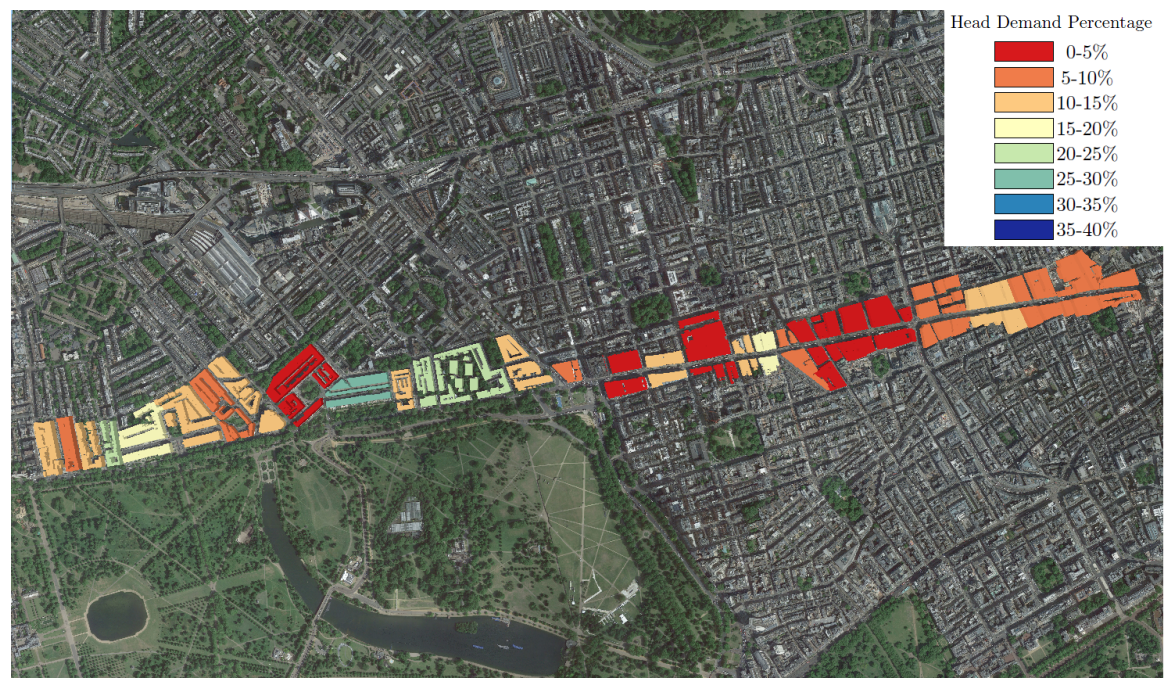

Figure 26. Map of the building cluster's annual heat demand compared to the heat extracted from the vertical boreholes in the Central Line in percentage.

\section{Conclusion}

A 1D model was developed using IDA Tunnel to model the climate conditions in the London Underground's (LU) Central Line station and tunnel, which is considered the busiest in the LU system. The simulation results are verified with measured temperature data in both the platforms and the tunnels. A 3D Comsol finite element model was developed to model thermal transient interactions between the subway tunnels and vertical boreholes, to assess their effectiveness in cooling the Central Line tunnels and platforms. The 1D Central Line and the 3D borehole models are co-simulated, through exchanging outer tunnel wall and soil temperature profiles, until both models yield a similar outer tunnel wall temperature, which indicates that both models have 
converged to a single solution. The 1D - 3D co-simulations converged in 11 iterations, where varying the iteration time interval between 1 month and 3 month yielded equivalent results, which allows for conducting annual simulations with fewer numbers of total iterations. The tunnel boreholes manage to cool the tunnel and platform temperatures in the Central Line model by $5{ }^{\circ} \mathrm{C}$ and $4.5^{\circ} \mathrm{C}$ respectively during summer conditions. A single tunnel borehole's heat extraction (9336 $\mathrm{kWh}$ ) was $9 \%$ slightly below a stand-alone borehole $(10177 \mathrm{kWh})$, because the tunnel boreholes thermally interfered along the sides of the tunnel, which slightly reduced their performance. This was a necessary compromise, since to better cool the tunnels, the boreholes were placed as close as possible to the tunnel outer walls. A single tunnel boreholes's annual heat extraction was found to be equivalent to the average annual heat demand of 1 UK household. Variations on the borehole arrangement and distance from the tunnel have shown that the optimum arrangement is having the parallel boreholes at a distance of $20 \mathrm{~cm}$ from the outer tunnel walls at each side, since the farther the distance the less heat will be extracted from the tunnels, which will consequently result in less cooling in the tunnels and stations.

A new design of partially insulated boreholes is examined to address the issue of having low heat demand in the buildings during summer, when the underground tunnels and stations require cooling. Results show that the partially insulated boreholes are able to provide building heating during winter conditions, and both building cooling and heating simultaneously during summer conditions while cooling the tunnels. The optimum dimensions of the partially insulated borehole was found to be $30 \mathrm{~m}$ for the non-insulated section next to the tunnel which extracts heat all around the year, while the other $70 \mathrm{~m}$ section alternates between extracting heat during winter conditions between January - April and October - December, and injecting heat into the soil (building cooling) during summer conditions between May - September. One partially insulated borehole can annually provide heating for $1.25 \mathrm{UK}$ households and an additional $6700 \mathrm{kWh}$ of building cooling, while the non-insulated borehole provides less building heating annually equivalent to 1 UK household. The results are further compared to building heating demand above a representative section of the Central Line spanning $4.8 \mathrm{~km}$. The buildings above this section are divided into 31 clusters. Results show that the boreholes can provide upto $74 \%$ of the hot water demand, which corresponds to the July heating demand across all the clusters. Retrofitting the tunnels with verticals boreholes was found to reduce building heating carbon emissions by 1067 tons of $\mathrm{CO}_{2}$ annually, when compared to gas boiler heating. Another aspect to take into consideration in future work is the diurnal variation of building heat demand, which dictates the borehole's operation schedule, and the optimum length of the boreholes. Further work is required on annual variations in fluid temperature and using realistic building load profiles. Also, an economic analysis and carbon foot comparison between the borehole's heat pumps and the traditional gas fired boilers in the buildings above the tunnels is essential to explore their benefits financially and environmentally. 


\section{References}

2014. "Renewable Heat Incentive." http://www.energysavingtrust.org.uk/domestic/domestic/renewableheat-incentive.

Adam, D., and R. Markiewicz. 2009. "Energy from earth-coupled structures, foundations, tunnels and sewers." Gotechnique 59 (No. 3): 229236.

ASHRAE. 2001. Handbook of fundenmentals. ASHRAE. American Society of Heating, Refrigerating and Air-Conditioning Engineers.

Bernier, M., A. Pinel, P. Labib, and R. Paillot. 2004. "A Multiple Load Aggregation Algortihm for Annual Hourly Simulations of GCHP Systems." HVACER Res. 10: 471-487.

Botelle, M., K. Payne, and B. Redhead. 2010. "Squeezing the heat out of Londons Tube." Proceedings of the ICE Civil Engineering Volume 163 (Issue 3): 114122.

Brandl, H. 2006. "Energy foundation and other thermo-active ground structures." Gotechnique 56 (No. 2): 81-122.

Brinckerhoff, Parsons. 2001. Subway environmental design handbook. Technical Report volume i. Transit Development Corporation. Technical report.

Burzynski, R., M. Crane, R. Yao, and V.M. Becerra. 2011. "Heat Demand Analysis Of Residential Development In London Connected To District Heating Scheme." In TSBE EngD Conference, Vol. 5thUniversity of Reading.

Carslaw, H. S., and J. C. Jeager. 1959. Conduction of Heat in Solids. second edition ed. Oxford: Oxford Press.

CIBSE. 2012. Energy Effeciency in Buildings. The Chartered Institution of Building Services Engineering. London. 3rd ed.

Connolly, D., H. Lund, B. V. Mathiesen, and M. Leahy. 2010. "A review of computer tools for analysing the integration of renewable energy into various energy systems." Applied Energy 87: 1059-1082.

Cui, P., H. Yang, and Z. H. Fang. 2006. "Heat Transfer Analysis of Ground Heat Exchangers with Inclined Boreholes." Appl. Therm. Eng. 26: 1169-1175.

DECC. 2011. The Micro-Generation Installation Standard. MCS 022: Ground Heat Exchanger Lookup Tables. Supplementary Material to MIS 3005. Issue 1.0. Department of Energy and Climate Change. London. Page 21.

DECC. 2013. United Kingdom Housing Energy Fact File. Technical report. London: Department of Energy and Climate Change.

DECC. 2015. Energy Consumption in the UK. Technical report. Department of Energy and Climate Change.

EQUA. 2006. Cooling the tube software comparision. Technical report. EQUA simulation AB. Technical report.

Eskilson. 1987. "Thermal Analysis of Heat Extraction Boreholes." Ph.D. thesis. University of Lund.

Fayegh, Seama, and Marc A. Rosen. 2012. "Modelling Thermally Interacting Multiple Boreholes with Variable Heating Strength." In World Sustainability Forum, Oshawa, Ontario: 2nd World Sustainability Forum.

Franzius, J. N., and N. Pralle. 2011. "Turning segmental tunnels into sources of renewable energy." Proceeding of ICE, Civil Engineering Vol. 164: 35-40.

Fry, V.A. 2009. "Lessons from London: regulation of open-loop ground source heat pumps in central London." Quarterly Journal of Engineering Geology and Hydrogeology 42: 325-34.

Garber, Denis, Ruchi Choudhary, and Kenichi Soga. 2013. "Risk based lifetime costs assessment of a ground source heat pump (GSHP) system design: Methodology and case study." Building and Environment 60: 66-80.

Gilbey, M. J., S. Duy, and J. A. Thompson. 2011. "The potential for heat recovery from London Underground stations and tunnels." In CIBSE Technical Symposium, .

Gilbey, M. J., S. Duffy, and J. A. Thompson. 2011. "The Potential for Heat Recovery from London Underground Stations and Tunnels." In CIBSE Technical Symposium, CIBSE.

Griffiths, E. 2006. "Baking Hot at Baker Street." Internet. London. http://news.bbc.co.uk/1/hi/england/london/5191604.stm.

Hellstrom, G. 1991. "Thermal Analysis of Duct Storage Systems." Ph.D. thesis. University of Lund.

Hikari, F., I. Ryuichi, and I. Takashi. 2004. "Improvements on Analytical Modeling for Vertical U-tube Ground Heat Exchangers." Geotherm. Resour Counc. Trans. 28: 73-77.

Ingresoll, L. R., and H. J. Plass. 1948. Theory of the ground pipe heat source for the heat pump. Heating, 
Piping \& Air Conditioning 20(7): 119-122.

Kavanaugh, S. P. 1995. "A Design Method for Commercial Ground Coupled Heat Pumps." ASHREA Trans. 101: 1088-1094.

Kavanaugh, S. P., and K. Rafferty. 1997. Ground-Source Heat Pumps Design of GeothermalSystems for Commercial and Industrial Buildings. Technical report. USA: American Society of Heating.

Kim, J.-Y., and K.-Y. Kim. 2009. ". Effects of vent shaft location on the ventilation performance in a subway tunnel." Wind Engineering and Industrial Aerodynamics 97: 174-179.

Mortada, Adnan, Ruchi Choudhary, and Kenichi Soga. 2015. "Thermal Modeling and Parametric Analysis of Underground Rail Systems." In Energy Procedia, Vol. Volume 78Pages 22622267. 6th International Building Physics Conference, IBPC 2015.

Nicholson, Duncan P., Chen Qing, Mike de Silva, Alan Winter, and Ralf Winterling. 2014. The Design of Thermal Tunnel Energy Segments for Crossrail. Technical report. Crossrail.

Nora, Catolico, Ge Shemin, and John S. McCartney. 2016. "Numerical Modeling of a Soil Borehole Thermal Energy Storage System." Vadose Zone Journal 15 (1): 1-17.

Schneider, M., and C. Moormann. 2010. "GeoTU6 a geothermal research project for tunnels." Tunnel pp 14-21.

Spitler, J. D. 2000. "A Design Tool For Commercial Building Ground Loop Heat Exchangers." In The Fourth International Heat Pumps in Cold Climates Conference, Quebec.

TfL. 2010. Rolling Stock Data Sheet. 2nd edition. Transport for London. Technical report.

TfL. 2011. Analyzing passengers' onward travel patterns. Transport for London. Technical report. TfL. Technical report.

TfL. 2014. "TFL JOINS DANONE IN GIVING OUT BOTTLES OF EVIAN ON THE TUBE." Internet. London. https://tfl.gov.uk/info-for/media/press-releases/2014/july/tfl-joins-danone-in-giving-outbottles-of-evian-on-the-tube.

Webb, P. J., K.and Amis T. Amatya, B.and Soga, C. Davidson, and P. . Payne. 2009. "Energy pile test at Lambeth College, London: geotechnical and thermodynamic aspects of pile response to heat cycles." In Gotechnique, Vol. Volume 59 of Issue 3237-248. Institution of Civil Engineers. Institution of Civil Engineers. april.

Yavuzturk. 1999. "1999." Ph.D. thesis. Oklahoma State University.

Yi, H., M.and Yang, N. Diao, J. Liu, and Z. Fang. 2010. "A New Model and Analytical SSolution for Borehole and Pile Ground Heat Exchangers." International Journal for Heat Mass Transfer 53: 2593-601.

Yi, Man, Cui Ping, and Fang Zhaohong. 2012. Heat Transfer Modeling of the Ground Heat Exchangers for the Ground-Coupled Heat Pump Systems, Modeling and Optimization of Renewable Energy Systems. no. ISBN: 978-953-51-0600-5. InTech.

Zeng, H. Y., N. R. Diao, and Z. Fang. 2002. "A Finite Line-Source Model for Boreholes in Geothermal Heat Exchangers." Heat Transf. Asian Res. 31: 558-567.

Zhang, Yi, R. Choudhary, and K. Soga. 2015. "Influence of GSHP system design parameters on the geothermal application capacity and electricity consumption at city-scale for Westminster, London." Energy and Buildings 106: 3-12. 